\title{
Formaldehyde as a Promising C1 Source: The Instrumental Role of Biocatalysis for Stereocontrolled Reactions
}

\author{
Sarah Desmons, Regis Faure, and Sébastien Bontemps
}

\section{Just Accepted}

"Just Accepted" manuscripts have been peer-reviewed and accepted for publication. They are posted online prior to technical editing, formatting for publication and author proofing. The American Chemical Society provides "Just Accepted" as a service to the research community to expedite the dissemination of scientific material as soon as possible after acceptance. "Just Accepted" manuscripts appear in full in PDF format accompanied by an HTML abstract. "Just Accepted" manuscripts have been fully peer reviewed, but should not be considered the official version of record. They are citable by the Digital Object Identifier (DOI®). "Just Accepted" is an optional service offered to authors. Therefore, the "Just Accepted" Web site may not include all articles that will be published in the journal. After a manuscript is technically edited and formatted, it will be removed from the "Just Accepted" Web site and published as an ASAP article. Note that technical editing may introduce minor changes to the manuscript text and/or graphics which could affect content, and all legal disclaimers and ethical guidelines that apply to the journal pertain. ACS cannot be held responsible for errors or consequences arising from the use of information contained in these "Just Accepted" manuscripts. 


\title{
Formaldehyde as a Promising $C_{1}$ Source: The Instrumental Role of Biocatalysis for Stereocontrolled Reactions
}

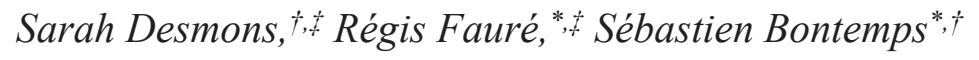 \\ †LCC-CNRS, Université de Toulouse, CNRS, Toulouse, France \\ †TBI, Université de Toulouse, CNRS, INRA, INSA, Toulouse, France
}

Corresponding Authors

*E-mail: regis.faure@,insa-toulouse.fr (R.F.)

*E-mail: sebastien.bontemps@1cc-toulouse.fr (S.B.)

\begin{abstract}
:
In the context of the depletion of fossil resources, formaldehyde is an emerging $C_{1}$ source exhibiting high and versatile reactivity, compared to the most studied $\mathrm{C}_{1}$ molecules $\left(\mathrm{CO}_{2}, \mathrm{CO}\right.$, $\mathrm{HCOOH}$, and $\mathrm{CH}_{4}$ ). In the present mini-review, we show that biocatalysis is an ideal approach to control the reactivity of formaldehyde and to use its great potential as a platform for the synthesis of value-added chiral products. The ability of aldolases and ThDP-dependent enzymes to catalyse stereocontrolled carbon-carbon bond formation with formaldehyde are shown to involve aldol and umpolung reactivity. The synergetic combination of i) enzyme discovery, ii) mechanism understanding, and iii) enzyme engineering provides highly stereospecific biocatalysts of increasing interest for synthetic chemistry.
\end{abstract}

KEYWORDS: formaldehyde, enzyme, aldolisation, umpolung reaction, carbon-carbon bond formation, selectivity, carbohydrate, cascade 


\section{Table of Contents}

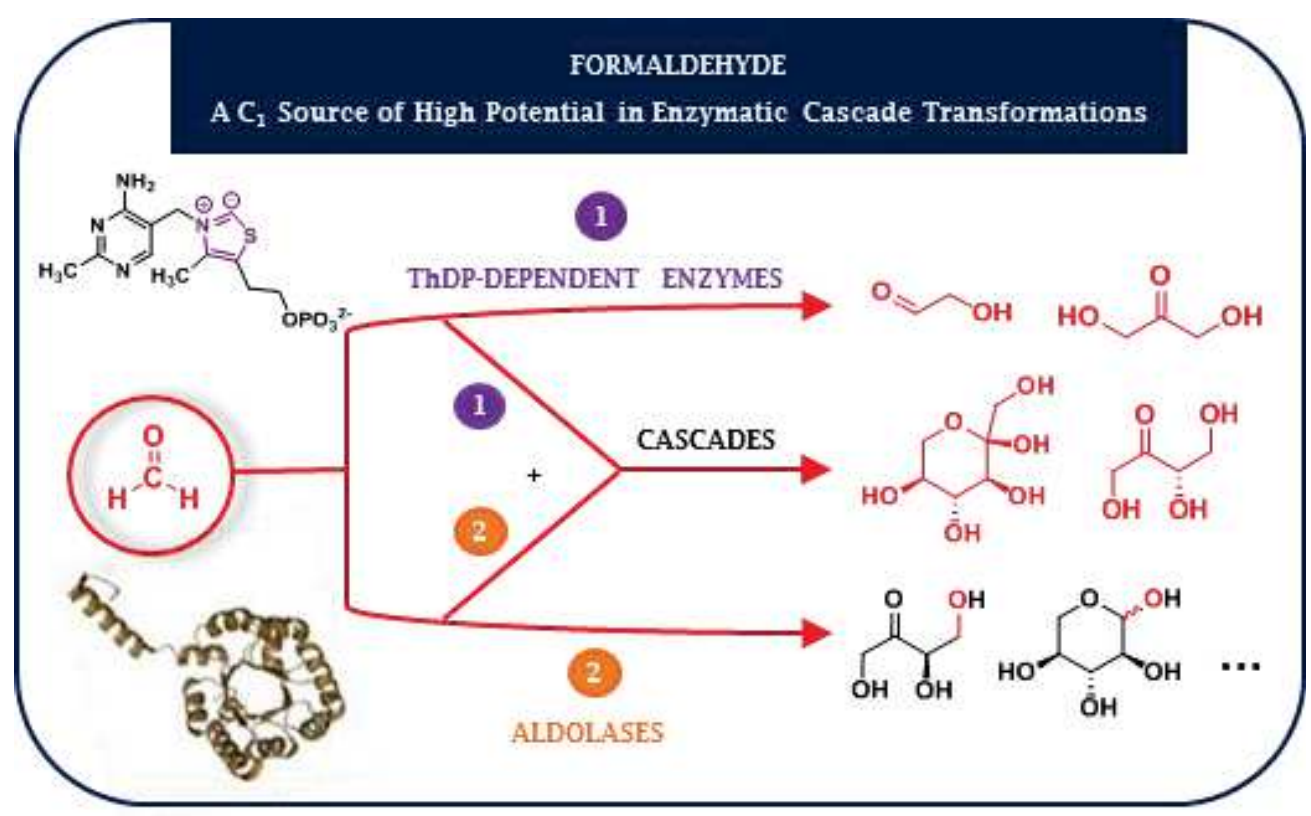




\section{INTRODUCTION}

\subsection{Formaldehyde: discovery and achiral use}

Butlerov discovered formaldehyde $(\mathrm{HCHO})$ in 1859 when studying methylene acetate hydrolysis. ${ }^{1}$ It was also the first polyatomic molecule detected in space by astrophysicists. For the chemical industry, formaldehyde is an important building block and more than 20 million tons of it are produced each year, mostly from partial oxidation of methanol. ${ }^{1}$ Its price is indexed on that of methanol and on regional markets. Formaldehyde is used as a cross-linking agent in resins (e.g. phenol-, urea- and melamine-resins, etc.). In these condensation reactions, it is used as a hydroxymethylene or methylene source. It is noteworthy that its slow and constant release from the wood-derived products is responsible for indoor pollution. ${ }^{2-3}$

\subsection{Scope of this review: aldol and umpolung reactions with formaldehyde}

Beyond its large scale achiral industrial use, formaldehyde is implicated in chiral processes involving aldolisation and umpolung activation. The formose reaction (FR) is a particular case of umpolung, which consists in oligo- or polymerization of formaldehyde. Previous reviews describe chemocatalyzed i) asymmetric aldolisations of formaldehyde, ${ }^{4}$ as well as ii) FR. ${ }^{5-6}$ Chemo- and biocatalyzed aldol and umpolung reactions of carbonyl compounds were described as major C-C bond formation processes, as part of a larger review highlighting the complementary roles of chemo- and biocatalysis in retrosynthesis. ${ }^{7}$ The high potential of aldolase in aldol reaction was recently highlighted in detail. ${ }^{8-10}$

Because formaldehyde is of high interest as a $C_{1}$ source for the synthesis of value-added chemicals, the objective of the present review is to focus on this peculiar molecule and its biocatalytic transformations. Herein we thus provide an exhaustive overview of enzymecatalyzed aldol and umpolung reactions with formaldehyde to generate complex chiral products.

The present publication highlights the importance of i) enzyme discovery, ii) mechanism understanding, and iii) enzyme engineering. The combination of these three approaches is instrumental in providing highly stereospecific biocatalysts dedicated to synthetic chemistry. Moreover, these selective systems are combined in cascade reactions without the need of protection/deprotection cycle nor isolation of intermediates to promote the generation of valueadded products. With the examples developed herein, we wish to highlight the complementarity between synthetic chemistry and biochemistry. 


\subsection{Formaldehyde: a $C_{1}$ source of high potential}

Formaldehyde transformation is highly rewarding because it potentially gives rise to an important gain in complexity: from a simple achiral $\mathrm{C}_{1}$ building block, $\mathrm{C}-\mathrm{C}$ bonds are formed and asymmetric carbon centers can be generated. In living organisms, formaldehyde is i) a key metabolite in aerobic methylotrophic organisms via its oxidation to the formyl level, ${ }^{11-12}$ and ii) the main source of methylene in carbon assimilation pathways. ${ }^{13}$ In the context of the depletion of fossil resources, an increasing interest is dedicated to $C_{1}$ chemistry. ${ }^{14-16}$ While the most studied $\mathrm{C}_{1}$ molecules remain $\mathrm{CO}_{2}, \mathrm{CO}, \mathrm{HCOOH}$, and $\mathrm{CH}_{4}, \mathrm{HCHO}$ is an emerging $\mathrm{C}_{1}$ source due to recent developments toward its production either from biomass ${ }^{17-19}$ or from $\mathrm{CO}_{2} \cdot{ }^{20-23}$ Contrarily to the cited $\mathrm{C}_{1}$ molecules, formaldehyde is a particularly versatile and reactive substrate which offers great promise for the synthesis of value-added chiral products.

\subsection{Formaldehyde: a challenging substrate}

Formaldehyde is also challenging to use and transform: i) it is a gas under atmospheric conditions and is usually used in vitro as an aqueous solution -so-called formalin solutionfeaturing a rather ill-defined composition and exhibiting stability issues over time; and ii) formaldehyde is a symmetrical and very reactive molecule. While these challenges appear perfectly fitted for the high selectivity of enzymatic catalysis, the control of the high reactivity of formaldehyde is the most important issue to solve for biocatalytic transformation of HCHO. Undesired reaction of formaldehyde with nucleophilic residues leads to protein deactivation ${ }^{24-}$ ${ }^{29}$ or even denaturation by cross-linking if formaldehyde reacts with two residues. ${ }^{30-34} \mathrm{We}$ wish to show that the discovery and engineering of enzymes are instrumental to address this issue and impressive progress enable some enzymes to better "handle" formaldehyde.

\subsection{Description of aldol and umpolung reactions: formaldehyde as a hydroxymethylating agent}

In aldol reaction, formaldehyde reacts with an enolizable carbonyl function giving rise to a $\gamma$ hydroxycarbonyl. In this reaction the generated asymmetric carbon center is the $C \beta$ of the carbonyl donor reactant and not the $\mathrm{C} \gamma$ arising from formaldehyde (Figure 1a). Few aldolases, described in part 2 , are able to catalyze such reaction with formaldehyde.

Umpolung refers to polarity inversion. In the present case, this powerful method concerns the activation of the $\mathrm{C} \alpha$ of a carbonyl function giving rise to a $\beta$-hydroxycarbonyl compound. The resulting product is enolizable and can subsequently be engaged in aldol reactions to increase the level of complexity of the final molecule (Figure 1b). When formaldehyde is used as an 
acceptor, the $C \beta$ center arises from formaldehyde. While the intermediate is not chiral, the final product of the cascade is an asymmetric molecule in which the chiral center arises from formaldehyde (Figure 1b). A very particular case of this umpolung + aldolisation cascade is if all carbonyl substrates are formaldehyde. The reaction is then called formose reaction (FR) and leads to the de novo formation of carbohydrate derivatives (Figure 1c). These transformations are described in part 3.

\section{Chiral transformations with formaldehyde: hydroxymethylation}

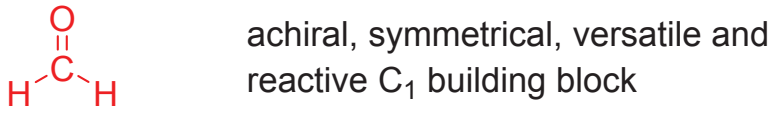

a) Aldolisation at $\mathrm{C} \beta$<smiles>[R]C(=O)C([R])C1CC1</smiles><smiles>CCC(C)C=O</smiles><smiles>[R]C(=O)C([R])O</smiles>

b) Umpolung at $\mathrm{C} \alpha$ followed by aldolisation at $C \beta$

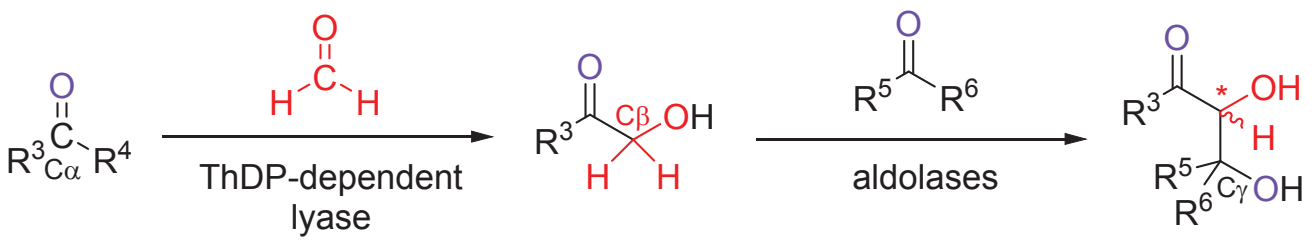

c) Formose reaction: umpolung + aldolisation with $R^{3}=R^{4}=R^{5}=R^{6}=H$

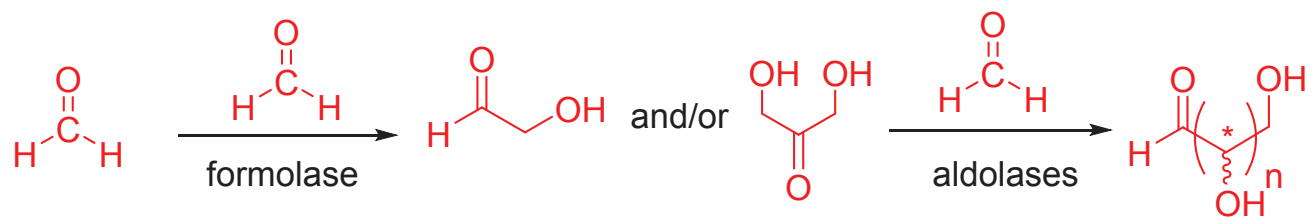

Figure 1. Enzyme-catalyzed transformations of formaldehyde: a) aldol reaction, b) cascade of umpolung and aldol reactions, c) formose reaction

\section{TRANSFORMATION OF FORMALDEHYDE BY ALDOLASES}

Aldolases belong to the $\mathrm{C}-\mathrm{C}$ bond forming lyase or transferase family and catalyze aldol reactions. The general mechanisms of action of these classes of aldolase currently known are presented hereafter (Figure 2). 


\subsection{Mechanisms}

Aldol reaction concerns the formation of a $\mathrm{C}-\mathrm{C}$ bond between an enolizable carbonyl compound, referred as the donor substrate, and an acceptor. Enolization process generates a nucleophilic carbon atom, which adds to the electrophilic carbonyl function of the acceptor. The donor substrate can be activated according to three different mechanisms, presented in the general scheme in Figure 2. In each case, the $\mathrm{C}-\mathrm{C}$ bond formation step is depicted. For the class I aldolases, the donor substrate is activated by a lysine residue, forming an enamine intermediate, while for the class II, a Lewis acidic metal co-factor promotes an enediolate form. ${ }^{8-9,}$, 35-39 The third possible activation concerns hydroxymethyl pyridoxal 5'-phosphate (PLP)-dependent enzyme. The PLP co-enzyme activates the donor substrate to form a quinoide aldimine intermediate. ${ }^{40-41}$ Structurally, formaldehyde cannot be a donor substrate because it is not enolizable. However, it is a good electrophile and thus a reactive acceptor for a nucleophilic attack from these three key intermediates. Furthermore, the small size and symmetry of formaldehyde are challenges for controlling its approach and ultimately its reactivity.

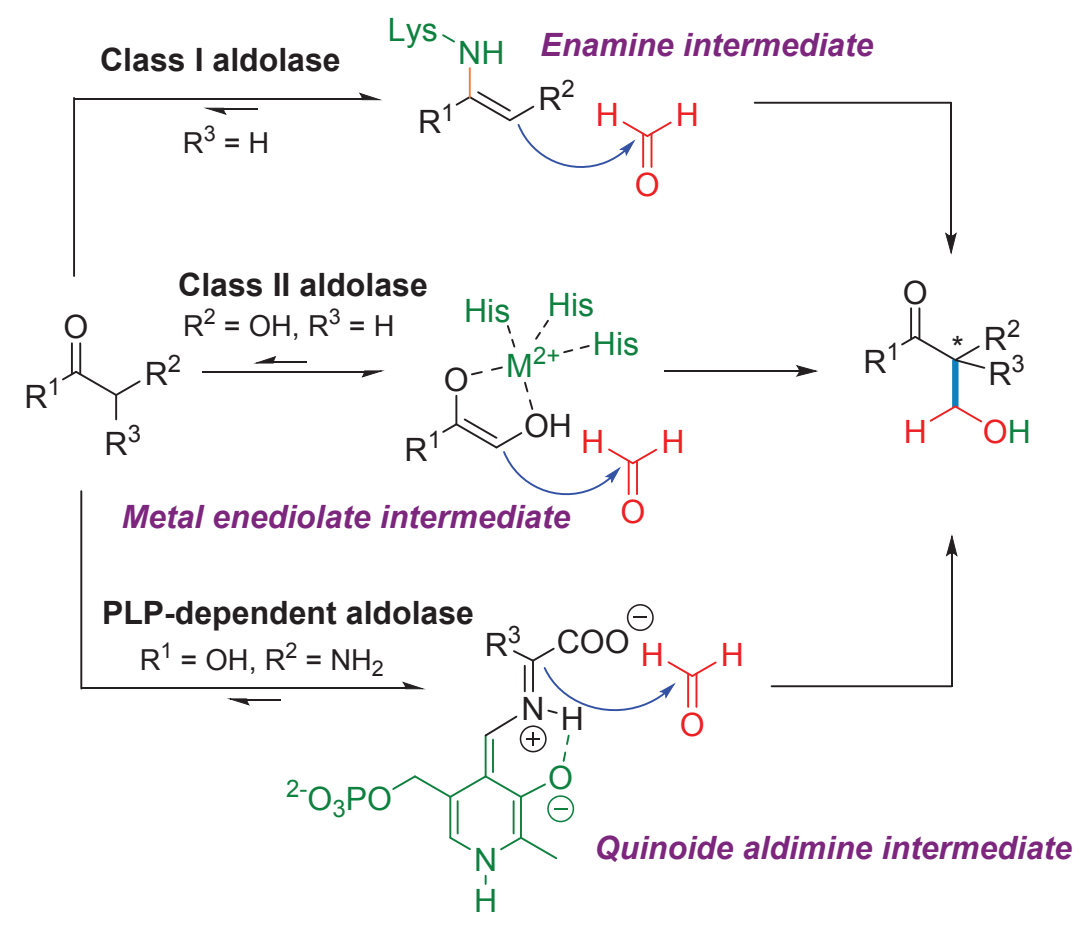

Figure 2. General scheme of aldolisation catalyzed by class I, class II and PLP-dependent aldolases 
In each mechanism, the chiral center $\mathrm{C} \beta$ is generated during the formation of the $\mathrm{C}-\mathrm{C}$ bond and the donor substrate is primarily activated by the catalytic center. Thanks to these bindings, the degree of freedom of the donor is reduced and the enzyme pocket orientates preferentially one face of the donor to the incoming acceptor to insure the stereocontrol. As a consequence, aldolases display high donor substrate specificity. The spatial arrangement of the incoming acceptor appears less constrained by the enzyme, leading to broader acceptor scopes. Formaldehyde is a good acceptor, however it may also interact with various nucleophilic residues. For instance, class I aldolase are particularly sensitive to formaldehyde concentration, because the catalytic lysine residue can react with formaldehyde which inhibits or inactivates the enzyme.

\subsection{Transformation of formaldehyde by aldolases: impressive stereocontrolled reactions and scope improvement}

Among the class I, class II and PLP-dependent aldolases, few of them have been shown to tolerate formaldehyde as acceptor substrate. These enzymes are presented hereafter. Although, their reactivities with other acceptor are mentioned, the focus is on the aldol reaction with formaldehyde. The product yields are mentioned when they were reported.

\subsubsection{Pyruvate and phenylpyruvic acid-dependent aldolases}

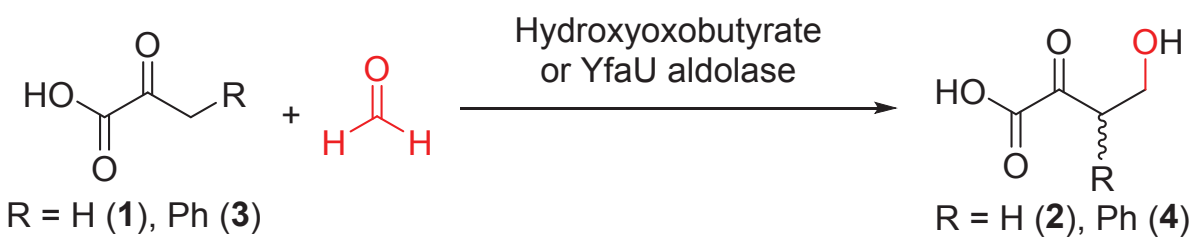

Figure 3. Pyruvate aldolase catalysis: synthesis of compounds 2 and 4

Hydroxyoxobutyrate aldolase (EC 4.1.2.1) was discovered in 1952 in mammalian organisms and extracted from beef liver. ${ }^{42}$ It was later reclassified in the enzyme family of 4-hydroxy-2oxoglutarate aldolase (EC 4.1.3.16). It is a pyruvate-dependent class I aldolase, which catalyzes the aldol addition of pyruvic acid (1) to formaldehyde (Figure 3). The formation of $\alpha$-keto- $\gamma$ hydroxybutyric acid (2) was evidenced by the $\gamma$-lactone form of the product. Formaldehyde 
concentration is rate-determining but an excess of formaldehyde initiates side reactions (up to $0.073 \mathrm{M}$ of formaldehyde is tolerated without activity loss). Phenylpyruvic acid (3) is also a donor substrate leading to $\alpha$-keto- $\beta$-phenyl- $\gamma$-hydroxybutyric acid (4) as a product of the reaction (Figure 3). Despite further tests, no other donor substrates were found suitable with formaldehyde.

2-Keto-3-deoxy-L-rhamnonate class II aldolase (YfaU, EC 4.1.2.53) mutant of 2-keto-3deoxy-6-phosphogluconate aldolase (KDP), ${ }^{43-44}$ was produced as a soluble fusion protein, with its natural cofactor $\mathrm{Mg}^{2+}$. Compared to class I aldolases, ${ }^{42}$ this class II pyruvate aldolase was found to be more tolerant to higher formaldehyde concentration (up to $1.4 \mathrm{M}$ is tolerated). The reaction of sodium pyruvate (5) with formaldehyde affords sodium 4-hydroxy-2-oxobutanoate (6) in quantitative yield (Figure 4). A double condensation of formaldehyde, in particular when $\mathrm{Mg}^{2+}$ is replaced by $\mathrm{Ni}^{2+}$ or $\mathrm{Co}^{2+}$, affords 4-hydroxy-3-hydroxymethylene-2-oxobutanoate (7) in more than $60 \%$ yield (Figure $4 \mathrm{a}$ ). Y Y $\mathrm{f} U$ was then used in an elegant tandem reaction in combination with $(S)$ or $(R)$ selective transaminases to produce amino-acids in a stereocontrolled way: $(S)$ and $(R)$-homoserine (9) are obtained in 86 and $>95 \%$ yield respectively as unique enantiomer (Figure $4 b){ }^{45}$

a)

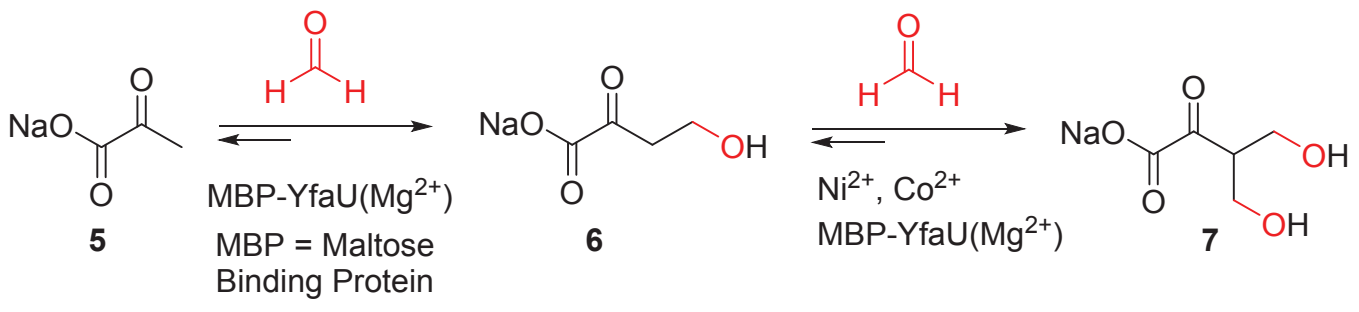

b)

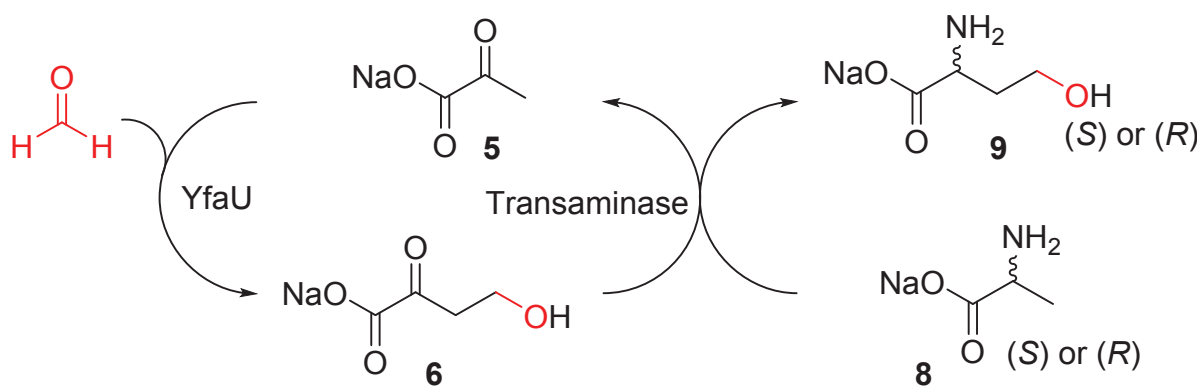

Figure 4. YfaU aldolase reaction with formaldehyde: a) synthesis of compound 7, b) synthesis of compound 9

\subsubsection{D-Ribulose 5-phosphate-dependent aldolase}

3-Hexulose phosphate synthase (HPS-aldolase, EC 4.1.2.43) is a class II aldolase found in aerobic methylotrophic bacteria and is involved in the ribulose monophosphate cycle. It 
catalyzes the aldol reaction between D-ribulose 5-phosphate (10) and formaldehyde, yielding D-arabinose 3-hexulose 6-phosphate (11, Figure 5). ${ }^{46}$ While compound $\mathbf{1 0}$ is the only suitable donor found over 20 tested, several other aliphatic and even aromatic aldehydes are acceptor substrates besides the natural acceptor formaldehyde. ${ }^{47}$

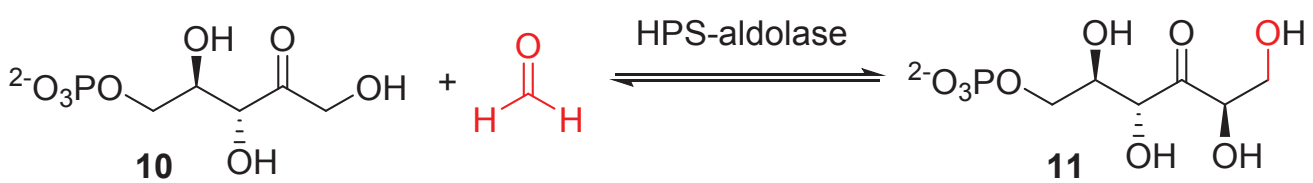

Figure 5. HPS-aldolase catalysis: synthesis of compound 11

\subsubsection{Pyridoxal 5'-phosphate-dependent aldolases}

a)

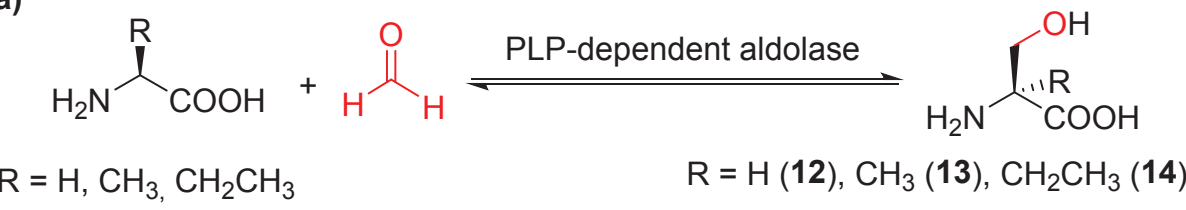<smiles>Cc1ncc(CO[Na])c([O-])c1C=O</smiles>

b)<smiles>Nc1nc(O)c2c(n1)NCC(CNCCO)C2</smiles>

$5,10-\mathrm{CH}_{2}-\mathrm{THF}$<smiles>Nc1nc(O)c2c(n1)NCC(CNc1ccc(C(=O)NC(CCC(=O)O)C(=O)O)cc1)N2</smiles>

Figure 6. PLP-dependent aldol reaction: a) synthesis of compounds 12-14 and structure of $P L P$ b) reversible THF reactivity toward formaldehyde

Serine hydroxymethyltransferase (SHMT, EC 2.1.2.1), found in prokaryotes and eukaryotes organisms, belongs to the glycine-dependent aldolase family. ${ }^{48}$ This enzyme catalyzes the reversible aldol transformation of glycine into serine (12) (Figure 6a). Formaldehyde is generated in the enzyme from 5,10- $\mathrm{CH}_{2}$-tetrahydrofolic acid (THF, Figure 6b). ${ }^{40}$

a-Methylserine hydroxymethyltransferase (MSHMT, EC 2.1.2.7) of E. coli whole-cell extract catalyzes the formation of $\alpha$-methyl-L-serine (13), in 73\% yield, from formaldehyde and a slight excess of D-alanine (Figure $6 \mathrm{a}){ }^{49}$ 
a-Methylserine aldolase catalyzes the enantioselective formation of $\alpha$-methyl-L-serine (13) and $\alpha$-ethyl-L-serine (14) in 95 and 96\% in situ yield, respectively (Figure 6a). ${ }^{50}$ The enzyme is inhibited by the use of more than $10 \mathrm{mM}$ of formaldehyde. In contrast with SHMT and MSHMT, this enzyme is, in vitro, THF-independent. ${ }^{50-52}$

\subsubsection{Acetaldehyde-dependent aldolase}

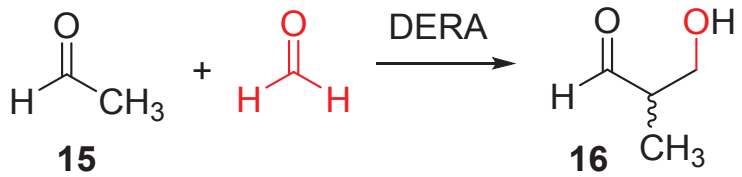

Figure 7. DERA aldolase catalysis: synthesis of compound 16

2-Deoxyribose-5-phosphate aldolase (DERA, EC 4.1.2.4) ${ }^{53}$ is isolated from animal tissues and microorganisms, and is currently commercially available. DERA from E. coli is a fairly stable class I aldolase and is the first discovered aldolase able to use an aldehyde as donor substrate. In vivo, DERA catalyzes the reversible aldol reaction between acetaldehyde and Dglyceraldehyde-3-phosphate (D-G3P) to generate D-2-deoxyribose-5-phosphate. Based on TLC analysis, formaldehyde and acetaldehyde (15) are presumed to react to afford 2-methyl-3hydroxy-propionaldehyde compound 16 (Figure 7).

\subsubsection{DHAP-dependent-aldolases}

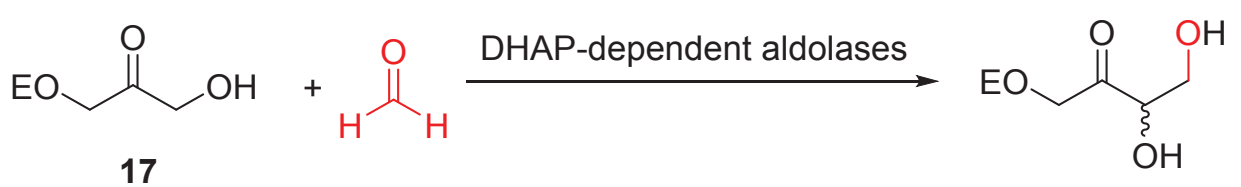

$$
\begin{aligned}
& \text { 18-S: FruA and TagA, } \mathrm{E}=\mathrm{PO}_{3}{ }^{2-} \\
& \text { 18-R: RhuA and } \mathrm{FucA}, \mathrm{E}=\mathrm{PO}_{3}{ }^{2-} \\
& \text { 19: } \mathrm{FruA}, \mathrm{E}=\mathrm{AsO}_{3}{ }^{2-}
\end{aligned}
$$

Figure 8. DHAP-dependent aldolase catalysis: synthesis of compounds 18 and 19 
D-Fructose-1,6-bisphosphate (FBP) aldolases (FruA, EC 4.1.2.13) are dihydroxyacetone phosphate (DHAP)-dependent aldolases. These glycolytic enzymes play a crucial role in glycolysis, glycogenesis and fructose metabolism. Class I FBP aldolase extracted from rabbit muscle, named RAMA, has been the most studied DHAP-dependent enzyme over the year. In 1989, RAMA was studied on a large variety of acceptor substrates. Among more than 50 different aldehydes, formaldehyde was shown to react with DHAP (17) to afford 18-S (Figure 8). ${ }^{54}$ Formaldehyde displays a good reactivity as an acceptor in RAMA-catalyzed aldol condensation, similar to its natural acceptor D-G3P (relative reactivity $v_{\text {rel }}$ of 105 and 100, respectively). RAMA withstands organic co-solvents up to $10 \% \mathrm{DMSO}$ or $20 \% \mathrm{EtOH}$ without significant loss of activity and is commercially available. It was the first aldolase exhibiting a large scope of acceptors and thus the first to be used as a synthetic biocatalyst. However, two main drawbacks remained: (i) deactivation of RAMA is fairly rapid in solution; (ii) the substrate specificity of the donor is almost only limited to DHAP that is an unstable and rather expensive substrate. ${ }^{55}$ Subsequently, two other FruA from Staphylococcus carnosus and Staphylococcus aureus were used in the same reaction. ${ }^{56-58}$ They exhibit higher thermo- and $\mathrm{pH}$ stability, and solvent tolerance than RAMA. S. carnosus was furthermore shown to tolerate DHAA, the arsenic analogue of DHAP leading to the synthesis of compound 19 (Figure 8). ${ }^{59}$ A class II FBP FruA from E. coli was also shown to catalyze the formation of $18-S$ in $72 \%$ yield. ${ }^{60}$

Tagatose 1,6-diphosphate aldolase (Tag A, EC 4.1.2.40): in the same study, class I TagA from E. coli and class I TagA from Bacillus licheniformis, were shown to afford 18-S in 70 and $68 \%$ conversion rate, respectively. ${ }^{60}$

\section{Rhamnulose 1-phosphate aldolase (RhuA, EC 4.1.2.19) and Fuculose 1-phosphate aldolase} (FucA, EC 4.1.2.17) are both bacterial aldolases from E. coli. Upon aldol reaction between DHAP and formaldehyde, the other isomer, compound $\mathbf{1 8 - R}$ is obtained in 81 and $73 \%$ yields with RhuA and FucA, respectively. Both of these enzymes are stable and tolerate organic cosolvent up to $30-50 \%$ of EtOH, DMF or DMSO. ${ }^{61}$ It was later reported that RhuA is able to accept the inexpensive non-phosphorylated DHA as a donor substrate, ${ }^{8,}{ }^{62}$ however, to our knowledge, no reaction has been yet reported with formaldehyde. Only a theoretical model have been considered for the aldol addition of DHA to formaldehyde. ${ }^{63}$

\subsubsection{DHA and derivatives-dependent aldolase: FSA, mutation and cascade}

D-Fructose-6-phosphate aldolase (FSA, EC 4.1.2.n). FSA has been discovered in 2001 from gene $f_{s} a A$ of $E$. coli genome and is so far of unknown physiological function. ${ }^{64}$ Although the 
amino acid sequence and the structure of FSA is evolutionary related to a transaldolase, this lyase exhibits the reactivity of a class I aldolase. The quaternary structure of FSA reveals high packing in a homodecamer form structure, which is believed to explain its high thermostability. ${ }^{65}$ Its subunit is folded into an $\alpha / \beta$ barrel. Its crystal structure with a glyceraldehyde compound (23) in purple is depicted in Figure 9a. The lysine residue K85 is covalently bond to compound $\mathbf{2 3}$ forming a hemiaminal en route to the formation of a Schiff base (Figures 2 and 9b). The highlighted alanine residues, A165 and A129 in cyan, have been subsequently subjected to mutagenesis to tune the enzyme properties (vide infra). FSA is produced on large scale, tolerates co-solvents (10-20\% of DMF, DMSO or acetonitrile) and is stable at room temperature or lower. The discovery and use of this enzyme is remarkable because i) it accepts several non-phosphorylated donors (dihydroxyacetone (DHA, 21), hydroxyacetone (HA, 22), glycolaldehyde (20, GA), 1-hydroxy-2-butanone), and acceptors, ${ }^{66-}$ ${ }^{68}$ and ii) it tolerates aldehyde and ketone donor substrate, larger ketols and bioisosteric ether. ${ }^{69-}$ ${ }^{70}$ Consequently, FSA is the first enzyme able to catalyze the production of ketose and aldose (Figures 10 and 11).
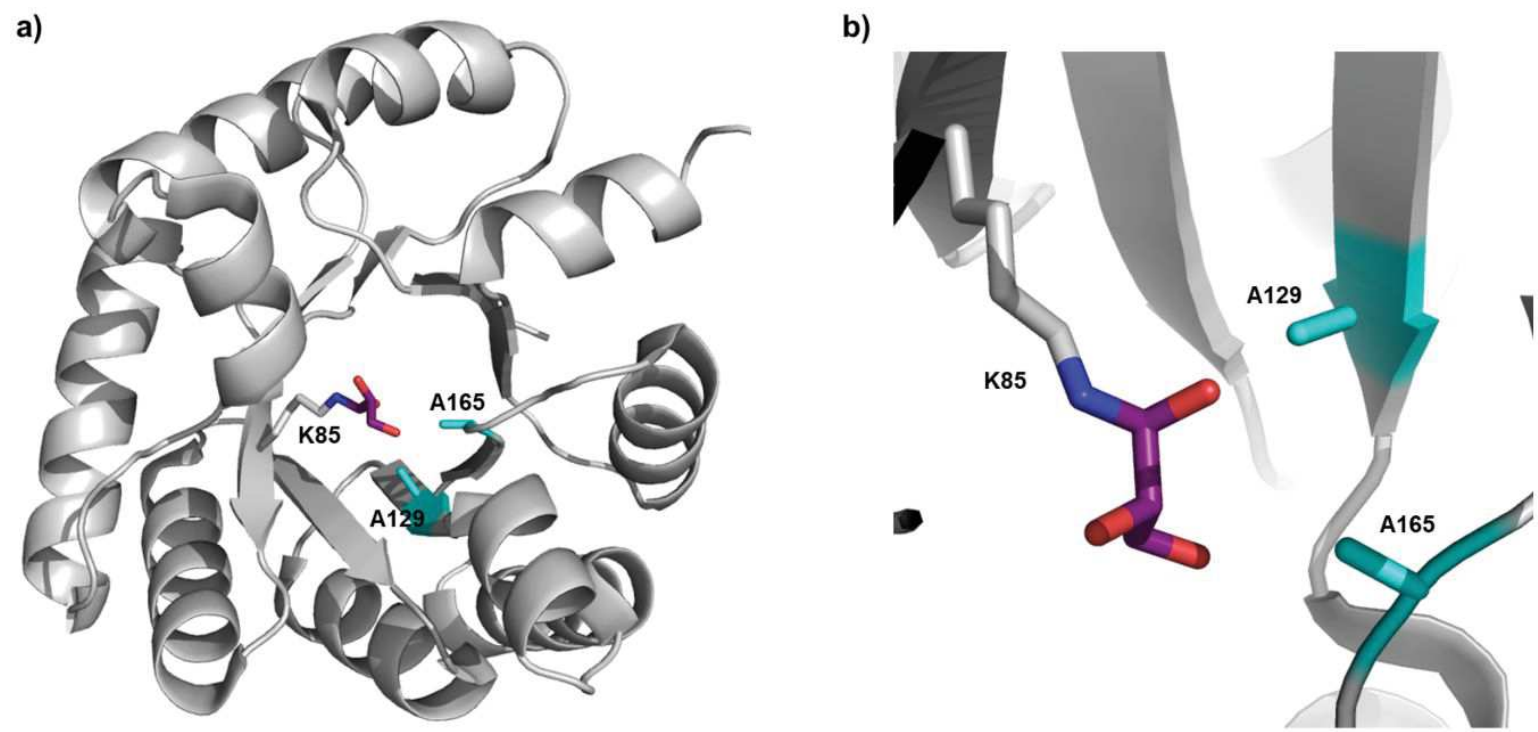

Figure 9. Views of the E. coli FSA (PDB ID: $1 L 6 W)$ : a) monomer and b) its active site with the catalytic lysine (K85) and glyceraldehyde (purple). ${ }^{65}$ The figure was prepared using PyMol Molecular Graphics System, v0.99 (Schrödinger). 


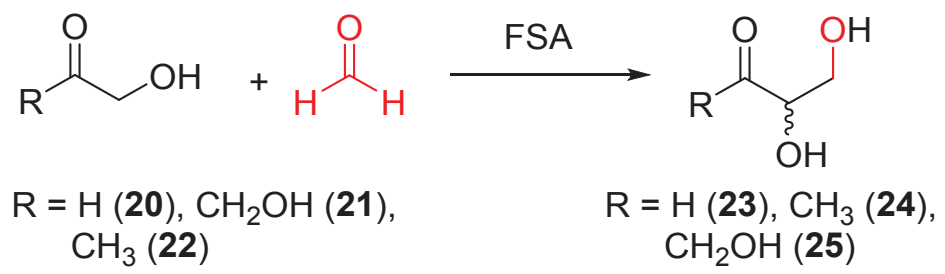

Figure 10. FSA aldolase catalysis: synthesis of compounds 23-25

\subsubsection{FSA-catalyzed aldol reaction of three donor substrates with formaldehyde: In} 2009, FSA was shown to catalyze the aldol reaction of GA as donor substrate with formaldehyde to successfully afford quasi-quantitatively L-glyceraldehyde (23) as the only enantiomer (Figure 11). ${ }^{69}$

In 2011, FSA was immobilized on the inexpensive inorganic support $\mathrm{Mg}_{2} \mathrm{Al}-\mathrm{NO}_{3}$ layered double hydroxide (LDH), with a loading of $90 \% .{ }^{71}$ In the aldol addition of HA to formaldehyde, the LDH-FSA is reused up to four times with $70-61 \%$ conversion and $100-87 \%$ of total FSA activity. 3,4-dihydroxybutan-2-one (24) is obtained in 95\% yield, as the only enantiomer (Figure 11).

$K_{\mathrm{M}}, k_{\text {cat }}$ and $k_{\text {cat }} / K_{\mathrm{M}}$ are the kinetic parameters used to compare the performances of different enzymes toward different substrates. According to the kinetic data presented in Table 1, DHA features less favorable kinetic parameters compare to HA with the wild-type FSA:67, 69, 72

i) The Michaelis constant $K_{\mathrm{M}}$ is indeed higher for DHA than for HA. $K_{\mathrm{M}}$ value reflects not only the affinity constant of the Michaelis complex (although it is often approximated to), but more precisely the catalytic steps up to the formation of the enzyme-substrate intermediate.

ii) The catalytic constant $k_{\text {cat }}$ (or turnover number) is 1 order of magnitude higher for HA than DHA.

iii) Overall, the catalytic efficiency $k_{\text {cat }} / K_{\mathrm{M}}$ is of 145 and $4 \mathrm{M}^{-1} \cdot \mathrm{s}^{-1}$ for HA and DHA, respectively.

In 2010, FSA was engineered to create FSA mono-mutant A129S to circumvent this lower reactivity toward DHA. ${ }^{72}$ As a result, the catalytic efficiency of FSA ${ }^{\mathrm{A} 129 \mathrm{~S}}$ toward DHA increased 17-fold compared to the wild-type enzyme (2.9-fold decrease of the $K_{\mathrm{M}}$ value and 6.6-fold increase of $k_{\text {cat }}$, Table 1). The mutant incorporates a serine, which is thought to stabilize the DHA donor and disfavors the access of the aldehydic acceptor to the donor part of the active site. FSA ${ }^{\mathrm{A} 129 \mathrm{~S}}$ catalyzes the reaction between DHA and formaldehyde to successfully afford L- 
erythrulose (25) in 68\% isolated yield as a unique enantiomer (Figure 11), despite poor kinetic parameters determined for formaldehyde (Table 1).<smiles>O=CC(O)CO</smiles>

23 quantitative<smiles>CC(=O)C(O)COc1ccccc1</smiles>

24 $95 \%$<smiles>O=C(CO)C(O)CO</smiles>

25

$68 \%$

Figure 11. Products of FSA-catalyzed transformation of formaldehyde

Table 1. Steady-state kinetic parameters of aldol reactions catalyzed by FSA wild-type and A $129 S^{69,72}$

\begin{tabular}{|l|l|l|l|l|l|l|}
\hline \multirow{2}{*}{ Substrate } & \multicolumn{3}{|c|}{ FSA wild-type } & \multicolumn{3}{c|}{ FSA $^{\text {A129S }}$} \\
\cline { 2 - 7 } & $\begin{array}{l}K_{\mathrm{M}} \\
(\mathrm{mM})\end{array}$ & $k_{\text {cat }}\left(\mathrm{s}^{-1}\right)$ & $\begin{array}{l}k_{\text {cat }} / K_{\mathrm{M}}\left(\mathrm{s}^{-1} \cdot \mathrm{mM}^{-}\right. \\
1\end{array}$ & $\begin{array}{l}K_{\mathrm{M}} \\
(\mathrm{mM})\end{array}$ & $k_{\text {cat }}\left(\mathrm{s}^{-1}\right)$ & $\begin{array}{l}k_{\text {cat }} / K_{\mathrm{M}}\left(\mathrm{s}^{-1} \cdot \mathrm{mM}^{-}\right. \\
1\end{array}$ \\
\hline $\mathrm{DHA}^{a}$ & 32 & 116 & 4 & 11 & 760 & 69 \\
\hline $\mathrm{HA}^{a}$ & 17.4 & 2527 & 145 & 22 & 899 & 41 \\
\hline $\mathrm{GA}^{a}$ & 0.20 & 16.5 & 83 & 0.18 & 4.4 & 25 \\
\hline $\begin{array}{l}\text { Formald } \\
\text { ehyde }^{b}\end{array}$ & nd & nd & nd & 77 & 27.7 & 0.4 \\
\hline
\end{tabular}

nd: not determined, ${ }^{a}$ donor substrate; ${ }^{b}$ acceptor substrate.

\subsubsection{Cascade reaction with FSA}

The access to orthogonal specificity of different enzymes and mutants enables cascade reactions leading to impressive complex transformations from simple building blocks. An efficient and elegant cascade reaction involving FSA and a kinase has been developed for the synthesis of four rare phosphorylated L-sugars (27-30, Figure 12a) from simple and achiral GA and formaldehyde. ${ }^{73}$ The cascade reaction involves a first FSA-catalyzed aldol reaction between GA and formaldehyde affording L-glyceraldehyde (23), isolated in 72\% yield. This expensive L-sugar is then phosphorylated thanks to glycerol kinase (GK), coupled with an ATP regenerating system affording the valuable L-glyceraldehyde-3-phosphate (26). The reaction of this substrate with four different donors leads to the phosphorylated sugars 27-30. 
The preparation of the rare L-xylopyranose (31) via stereoselective glycolaldehyde double addition to formaldehyde was recently reported (Figure 12b). ${ }^{74}$ A structure-guided site directed mutagenesis of the acceptor-binding site was used to design a FSA mutant able to perform this $\mathrm{C}_{1}+\mathrm{C}_{2}+\mathrm{C}_{2}$ addition. ${ }^{75}$ Different mutations were tested and the double mutant A129T/A165G appeared to be the most efficient $\mathrm{C}_{1}+\mathrm{C}_{2}+\mathrm{C}_{2}$ catalyst. Compound $\mathbf{3 1}$ was thus successfully prepared in $62 \%$ isolated yield as a unique enantiomer. Using a strategy of substrate confinement, the synthesis of $\mathbf{3 1}$ was further improved to an increased yield $>95 \%$ by using FSA $^{\mathrm{A} 129 \mathrm{~T} / \mathrm{S} 166 \mathrm{G} .}{ }^{76}$

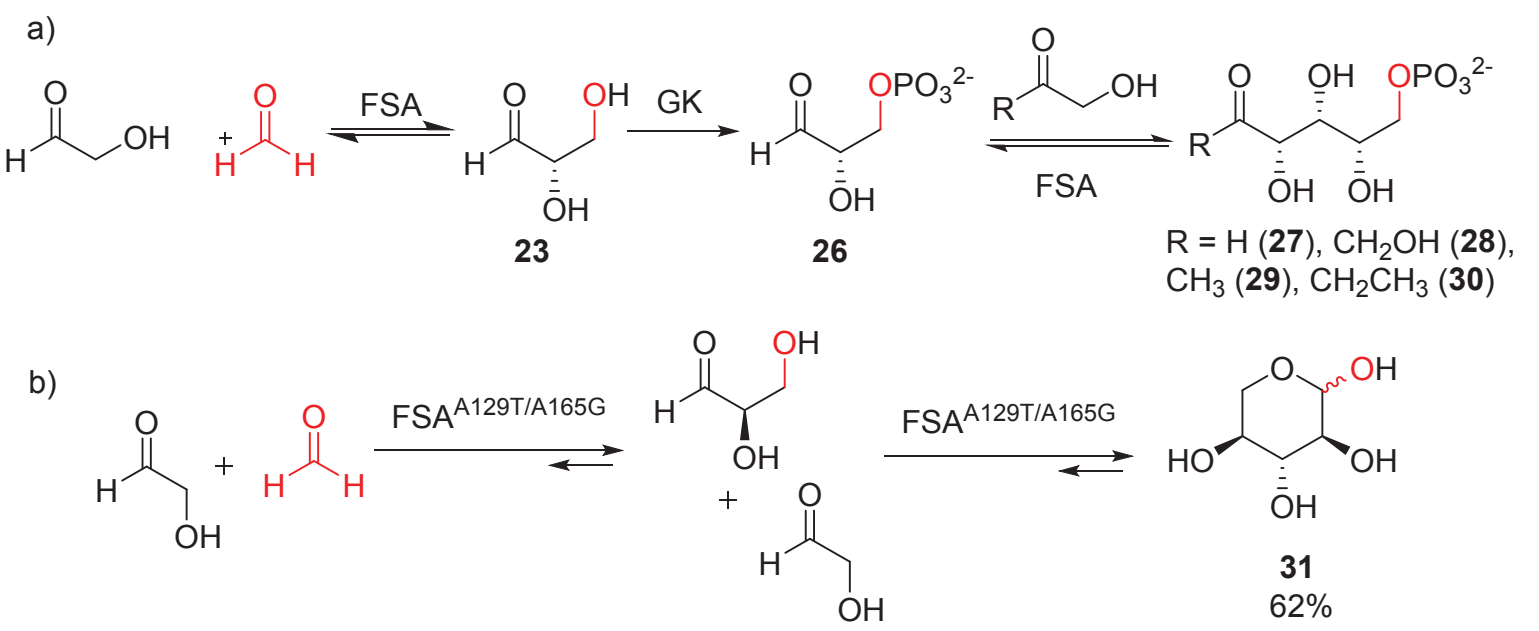

Figure 12. Cascade reactions involving FSA for the synthesis of complex structures: (a) synthesis of compounds 27-30, (b) synthesis of compound 31

Table 2 below is a summary of the presented aldolase-catalyzed reactions with formaldehyde along with the level of tolerance toward this acceptor substrate. The complexity of these transformations is impressive in absence of protective group. However, the use of such enzymes as synthetic biocatalysts would require further improvements. 
Table 2. Summary of aldolase reactions with formaldehyde and tolerance toward this acceptor substrate.<smiles>[R2]CC([R1])=O</smiles>

Donor substrate

Product

PRODUCT

ALDOLASE

[HCHO]

used in

product

synthesis

Inhibitory

(M)

(M)<smiles>O=C(O)C(=O)C(CO)c1ccccc1</smiles><smiles>O=C(O)C(=O)CCO</smiles>

Hydroxyoxobutyrate aldolase ${ }^{42}$

2-Keto-3-deoxy-L-rhamnonate class II aldolase (YfaU $)^{45}$<smiles>O=C(O)C(=O)C(CO)CO</smiles>

2-Keto-3-deoxy-L-rhamnonate class II aldolase (YfaU) ${ }^{45}$

1 $>1.4$<smiles>[R6]OC[C@@H](O)[C@H](O)C(=O)[C@H](O)CO</smiles>

3-Hexulose phosphate synthase (HPSaldolase $)^{46}$

0.000030 nd<smiles>CC(N)(CO)C(=O)O</smiles>

$\alpha$-Methylserine hydroxymethyltransferase $\left(\right.$ MSHMT) ${ }^{49}$ $\alpha$-Methylserine aldolase ${ }^{50,52,77}$
0.020 nd

0.010 


\section{UMPOLUNG ACTIVATION BY THIAMINE DIPHOSPHATE-DEPENDENT ENZYMES}

The umpolung activation of a carbonyl compound refers to the polarity inversion of the electrophilic $\mathrm{C} \alpha$. This is a powerful method for the formation of C-C bonds. The generated nucleophilic carbon adds to an electrophilic carbon center, such as the carbon of formaldehyde, giving rise to $\beta$-hydroxycarbonyl compounds (Figure 13a, step i)). However, only few species are able to perform such transformation. This field is dominated -but not limited to- carbene catalysts. ${ }^{78}$ In Nature, thiamine diphosphate (ThDP) -derived from vitamin B1- is the only known catalyst able to perform umpolung activation of carbonyl functions, thanks to a carbene activation moiety. ${ }^{79-81} \mathrm{ThDP}$ is a co-enzyme able to bond in the active site of various enzymes and plays the key catalytic role. Three different ThDP-containing enzymes give rise to reactivity with formaldehyde: transketolase (TK), benzaldehyde lyase (BAL), and engineered formolase (FLS). As depicted in the general Figure 13, the obtained $\beta$-hydroxycarbonyl product does not feature any chiral center, but an enolizable carbonyl moiety. Subsequent aldol reaction leads to chiral compounds in which the chiral carbon center is the carbon of the formaldehyde acceptor substrate (Figure 13a, step ii)). A particular case of umpolung is when formaldehyde is the only 
carbonyl substrate (i.e. both the donor and the acceptor), the reaction is then called formose reaction (FR, Figure 13b). The first enzyme-catalyzed formose reaction has been recently disclosed and later combined with aldolase to afford $\mathrm{C}_{4}$ and $\mathrm{C}_{6}$ carbohydrate with perfect stereocontrol. This represents an impressive gain in complexity starting from a simple achiral and symmetrical building block (vide infra).

a)

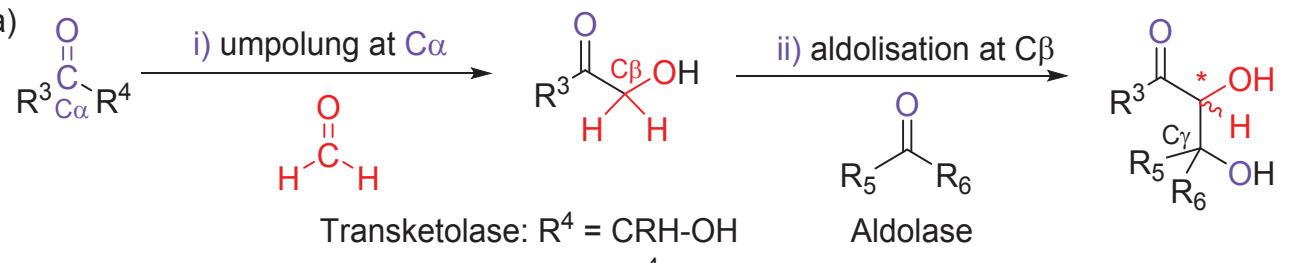

b) Formose reaction: umpolung + aldol with $R^{3}=R^{4}=R^{5}=R^{6}=H$

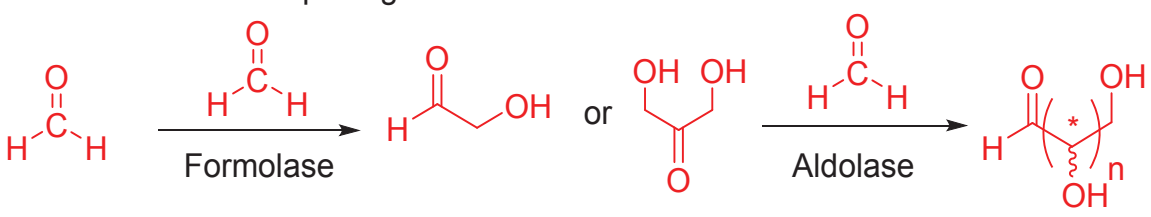

Figure 13. a) Umpolung and aldol cascade reactions, b) formose reaction

\section{ThDP: an in situ generated active carbenic center}

The exact mechanism of action of ThDP remained unclear until Breslow et al. reported that the catalysis is centered at the $\mathrm{C}-2$ of the thiazolium moiety. ${ }^{82} \mathrm{NMR}$ studies and deuterium exchange have shown that a glutamic residue favors the imino tautomer of ThDP leading to $\mathrm{C}-2$ deprotonation (Figure 14a). ${ }^{83-84}$ Once deprotonation takes place, the anionic charge is stabilized by the adjacent cationic nitrogen atom, generating an ylide or what was later recognized as a carbene, a very rare and elusive species to be observed in biological system. ${ }^{85-86}$ More precisely, Breslow et al. reported this breakthrough while studying ThDP-catalyzed decarboxylation of pyruvate. They proved the generation of a nucleophilic acylanion intermediate, which is now called Breslow intermediate (Figure 14b) and identified as the key species for the C-C bond formation. Indeed, thanks to the polarity inversion of the initial carbonyl function, the newly generated nucleophilic carbon can attack an electrophile moiety, leading to the carboligation between two initially electrophilic substrates. It is noteworthy that Breslow's discovery not only impacted the field of biocatalysis but also the development of carbenes as prototypical organocatalysts. $^{87-90}$ 
Although, pyruvate decarboxylate enzymes using ThDP as co-factor have been involved in C$\mathrm{C}$ bond formation, no example using formaldehyde have been reported so far. The related phenylpyruvate decarboxylate was tested with formaldehyde, however, no reactivity was detected. $^{91}$

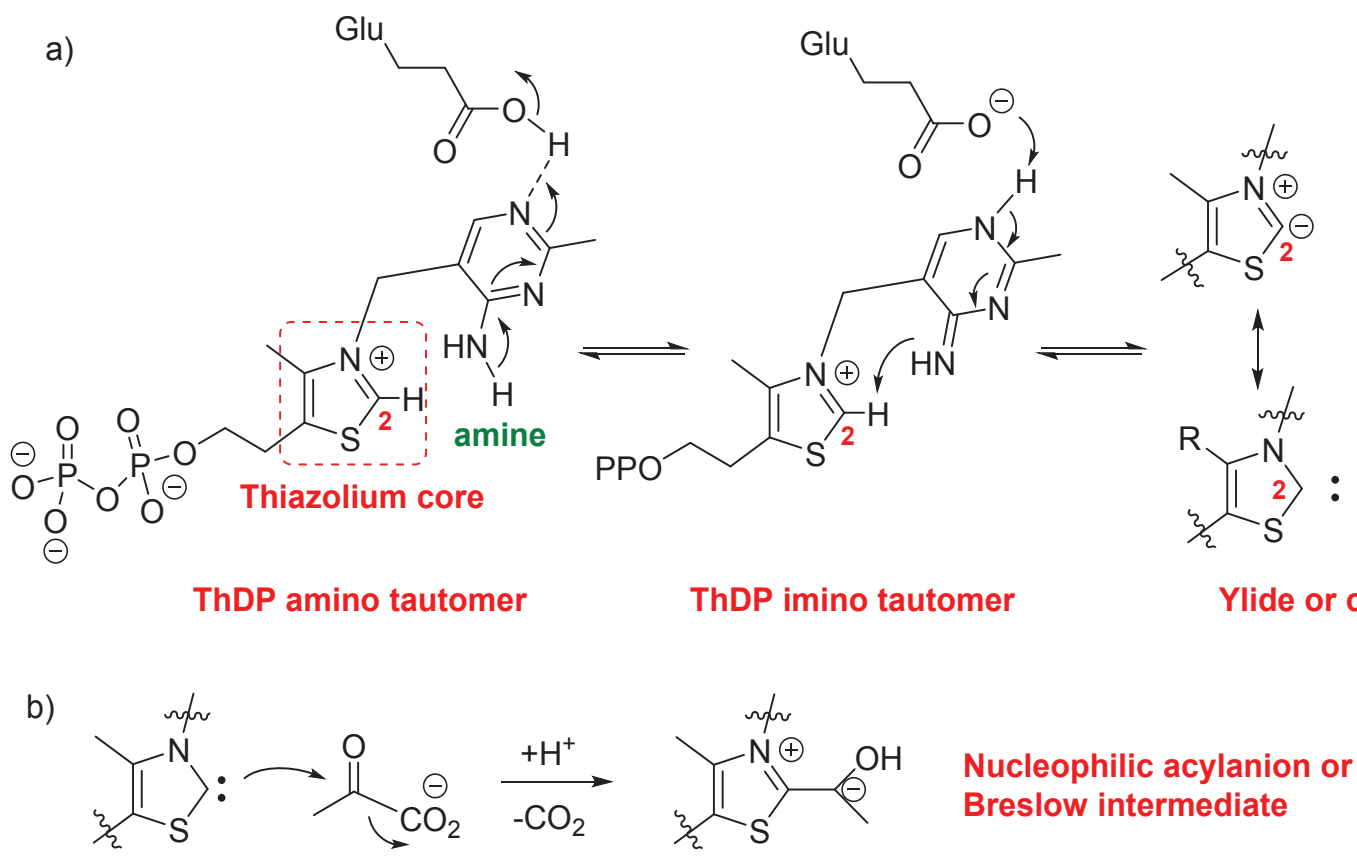

Figure 14. ThDP activation mode: a) carbene formation, b) Breslow intermediate generation

\subsection{Benzaldehyde lyase (BAL, EC 4.1.2.38)}

Benzaldehyde lyase is another type of lyase using ThDP as co-factor. It catalyzes C-C coupling between different benzaldehyde derivatives and formaldehyde in good to excellent yields with a scope of 11 different donors varying by aromatic groups R (Figure 15a). ${ }^{92}$ However, no reaction takes place in the case of fluorinated aromatic, indole and pyridinyl groups. To avoid benzoin condensation, an excess of formaldehyde is necessary. It is also reported that retrobenzoin condensation occurs only with the $R$ isomer of benzoin (32). Thanks to the reaction with formaldehyde, kinetic resolution is performed to isolate the $S$ benzoin enantiomer (Figure $15 b)$. 
a)<smiles>[R]C(=O)[CH+]C=O</smiles><smiles>[PH][PH]</smiles>

$\mathrm{H}_{2} \mathrm{O}, 20 \%$ DMSO<smiles>[R]C(=O)CO</smiles>
$\mathrm{R}$

$\mathbf{R}$<smiles></smiles>

Breslow intermediate

\begin{tabular}{|c|c|c|c|}
\hline $\mathbf{R}$ & $\begin{array}{c}\text { Isolated Yield } \\
\mathbf{( \% )}\end{array}$ & $\mathbf{R}$ & Isolated Yield (\%) \\
\hline $\mathrm{Ph}$ & 94 & $4-\mathrm{ClC}_{6} \mathrm{H}_{4}$ & 88 \\
\hline $4-\mathrm{MeC}_{6} \mathrm{H}_{4}$ & 94 & $4-\mathrm{OHC}_{6} \mathrm{H}_{4}$ & 89 \\
\hline $4-\mathrm{MeOC}_{6} \mathrm{H}_{4}$ & 91 & $2-\mathrm{Furanyl}$ & 77 \\
\hline $3-\mathrm{MeOC}_{6} \mathrm{H}_{4}$ & 92 & $4-\mathrm{Pyridinyl}$ & $<5$ \\
\hline $2-\mathrm{MeOC}_{6} \mathrm{H}_{4}$ & 68 & $3-\mathrm{Pyridinyl}$ & $<5$ \\
\hline $3-\mathrm{MeO}_{4}-$ & 51 & $2-\mathrm{FC}_{6} \mathrm{H}_{4}$ & $<5$ \\
\hline $\mathrm{OHC}_{6} \mathrm{H}_{3}$ & 83 & $2,4-\mathrm{F}_{2} \mathrm{C}_{6} \mathrm{H}_{3}$ & 15 \\
\hline $3-\mathrm{BrC}_{6} \mathrm{H}_{4}$ & 77 & Indole-3- & No reaction \\
\hline $2-\mathrm{ClC}_{6} \mathrm{H}_{4}$ & & carbaldehyde & \\
\hline
\end{tabular}

b)<smiles>O=C(c1ccccc1)[C@H](O)c1ccccc1</smiles>

$32 R / S$<smiles>C=O</smiles>

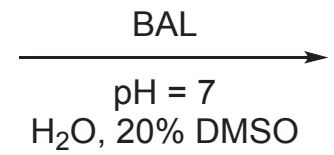

$\mathrm{H}_{2} \mathrm{O}, 20 \%$ DMSO<smiles>O=C(CO)c1ccccc1</smiles>

33

Figure 15. BAL-catalyzed umpolung reaction with formaldehyde: a) benzoin reaction, b) synthesis of compounds 33

\subsection{Transketolase (TK, EC 2.2.1.1)}

Transketolase is a key transferase in the natural pentose phosphate pathway. It is easily produced from E. coli and uses ThDP and $\mathrm{Mg}^{2+}\left(\right.$ or $\left.\mathrm{Ca}^{2+}\right)$ as cofactor. The role of ThDP is to break the C-C bond between the C-2 and C-3 of a number of ketose and aldose sugars (Figure 16). ${ }^{93}$ With this crucial step, TK catalyzes the reversible transfer of a hydroxyacetyl group to various carbonyl acceptors via the Breslow intermediate depicted in Figure $16 .{ }^{38}$ This nucleophilic hydroxyacetyl group notably reacts with formaldehyde to afford DHA (21) and the complementary aldehydic fragment (Figure 16). ${ }^{94}$ While the generated DHA is not chiral, 
it is only an intermediate that is further used as a $\mathrm{C}_{3}$ synthon in asymmetric transformations described hereafter in which the formed chiral center is the carbon atom arising from formaldehyde (Figure 17).<smiles>[R]C(=O)C=CC=O</smiles>
21<smiles></smiles>

Breslow intermediate

Figure 16. TK catalysis and activation mode: synthesis of compound 21

Two elegant cascade reactions use this general scheme to form DHA 21. ${ }^{95}$ The first cascade uses successively TK and FSA (Figure 17a). TK catalyzes the breaking of D-fructose-6phosphate (34) with formaldehyde to generate DHA and D-erythrose-4-phosphate (35). Concentration of formaldehyde has to be kept under $400 \mathrm{mM}$ in order to avoid TK inhibition. The two products are combined to afford the $\mathrm{C}_{7}$ D-sedoheptulose-7-phosphate (36), in 70\% yield in a FSA-catalyzed aldol reaction. The second cascade involves a similar TK-catalyzed C-C breaking from L-sorbose (37) and reaction with formaldehyde to provide L-threose (38) and DHA (Figure 17b). Upon conversion of DHA into DHAP (18), L-galacto-2-heptulose-1phosphate (39) is efficiently prepared in $80 \%$ yield from the aldol reaction of DHAP and Lthreose catalyzed by RAMA. 
a)

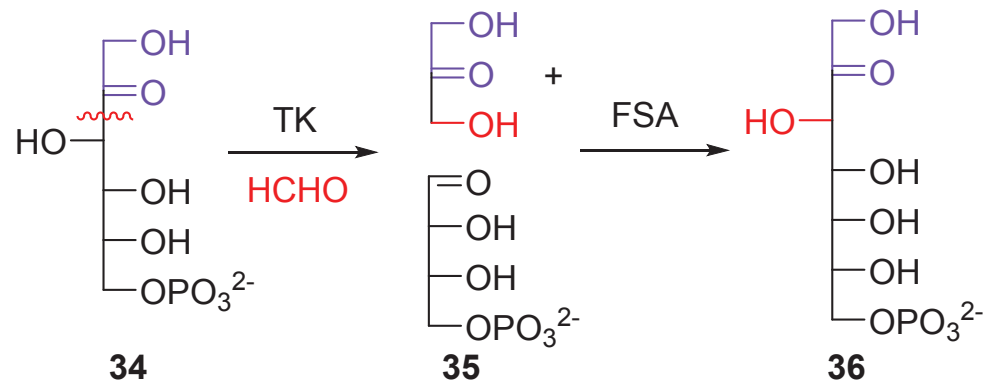

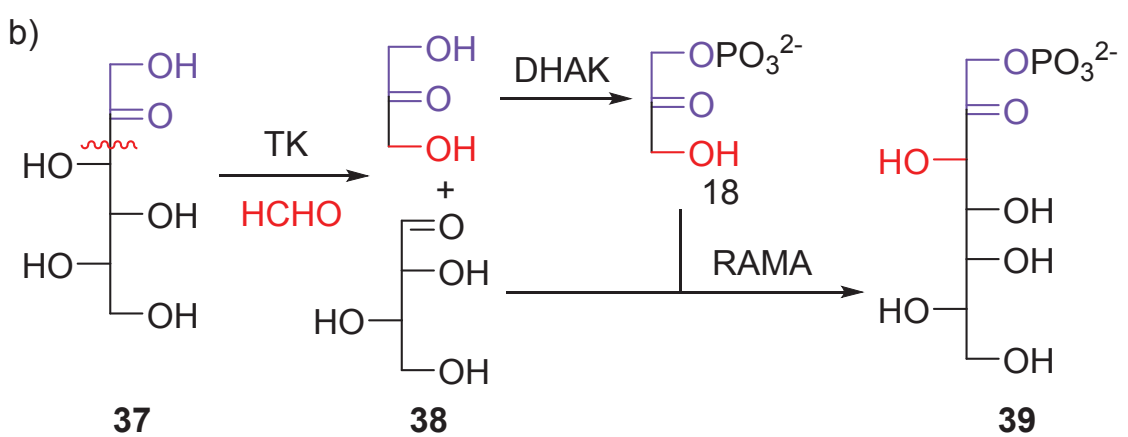

Figure 17. Cascade reactions involving TK transformation of formaldehyde into DHA intermediate: a) synthesis of compound 36, b) synthesis of compound 39

\subsection{Formolase}

\subsubsection{Formose reaction}

FR generates carbohydrates from the oligomerization of formaldehyde. Since its first report in 1861 by Butlerov, FR has attracted a large and continuous interest on a synthetic point of view ${ }^{5-6}$ and in prebiotic chemistry. ${ }^{96-98} \mathrm{FR}$ is a general term covering various type of reactions. Depending on the conditions and the catalyst used, the importance and occurrence of these reactions vary. FR catalyzed by inorganic base in the presence of co-activator gives rise to a complex mixture of carbohydrates due to the auto-catalytic nature of the process and of the multiple competitive reactions taking place (aldol, retro-aldol, Canizzaro, cross-Canizzaro, etc.). ${ }^{5-6}$ The use of carbene and in particular the pioneering work of Castell with thiamine enabled important progress in the selectivity for short chain carbohydrate..$^{99-102}$

The high specificity and selectivity of enzyme-catalyzed transformation represent a complementary approach to synthetic chemistry. It is particularly true with FR because it is an oligomerization process in which every product is a potential substrate. However, no enzyme is known to catalyze FR in vivo. The first engineered enzyme catalyzing FR leads selectively to $\mathrm{C}_{2}$ and $\mathrm{C}_{3}$ carbohydrates and was later used in a cascade reaction to afford $\mathrm{C}_{4}$ and $\mathrm{C}_{6}$ 
carbohydrates with perfect stereocontrol (vide infra). These two examples are described hereafter.

\subsubsection{Formolase: first enzyme-catalyzed formose reaction leading to $C_{2}$ and $C_{3}$ carbohydrates}

In 2015, the first enzyme-catalyzed FR was reported. The engineered formolase (FLS) catalyzes the di- and tri-merization of formaldehyde into GA and DHA, respectively (Figure 18, step a + a'). ${ }^{103}$ The production of DHA and GA was monitored over time in function of the concentration of introduced formaldehyde. ${ }^{104}$ The product profile is shown to be concentration-dependent. At high concentration of formaldehyde $(10 \mathrm{mM})$, DHA is obtained as the major product. At lower concentration of formaldehyde $(0.2 \mathrm{mM}), \mathrm{GA}$ is obtained as the main product. The mechanism of FR catalyzed by carbene is useful to understand these outcomes. ${ }^{105-106}$ ThDP activates formaldehyde to afford the simplest Breslow intermediate i) (Figure 18). This acylanion adds to a second equivalent of formaldehyde to afford another acylanion after proton migration from $\mathrm{C}$ - to O-atom ii). At this stage, the newly formed $\mathrm{C}_{2}$ compound can be released to afford GA and complete step a. Since it is an acylanion, it can also add to a third molecule of formaldehyde to generate the last intermediate iii) leading to DHA after release. This mechanism explains that a higher concentration of formaldehyde drives the reaction toward DHA via intermediate iii), whereas a lower concentration leads to GA. Additional investigations probed the involvement of GA as a valid intermediate in the formation of DHA. The use of ${ }^{13} \mathrm{C}$-labeled formaldehyde $(0.2,1$ and $10 \mathrm{mM})$ and unlabeled GA $(1 \mathrm{mM})$ gives rise to mix-labeled DHA. This proves that FLS is able to accept free GA to form the final DHA moiety upon reaction with one equivalent of formaldehyde. It is indeed possible that intermediate i) adds to the carbonyl of GA instead of formaldehyde. Since formaldehyde is a better acceptor, this situation arises when formaldehyde concentration is low. It is also possible that ThDP activates GA to form the intermediate ii) affording DHA via intermediate iii). 

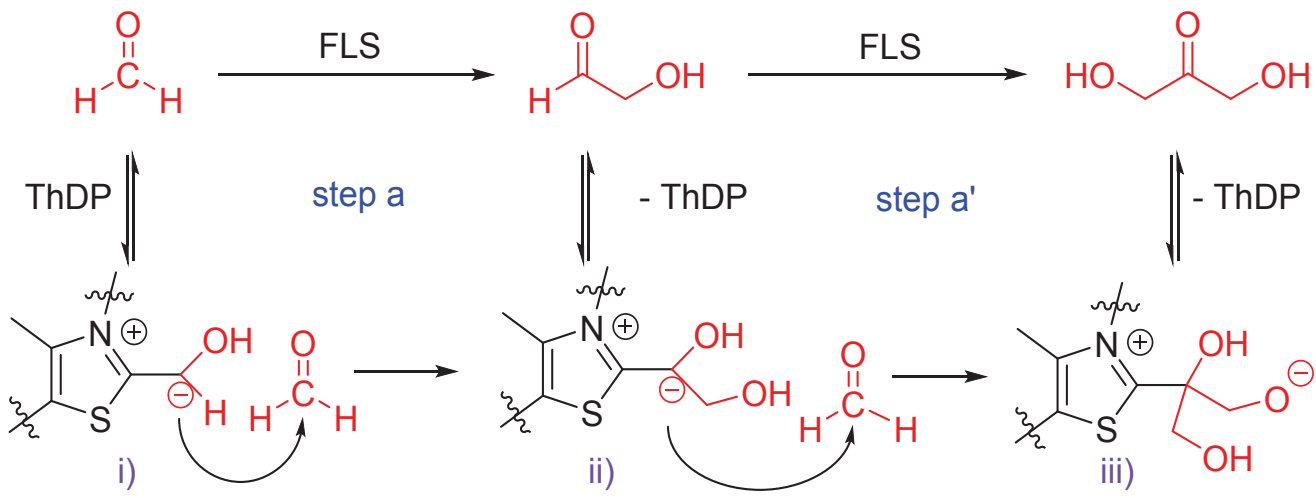

Figure 18. FLS-catalyzed formose reaction to GA and DHA

\subsubsection{FLS: an engineered enzyme from ThDP-dependent BAL}

FLS is an evolved enzyme that has been engineered from BAL from Pseudomonas fluorescens biovar $I^{103}$ As presented in 3.1, BAL is a ThDP-dependent enzyme which activates benzaldehyde to catalyze benzoin condensation as its natural transformation. Its ability to activate formaldehyde was thus hypothesized. Indeed, wild-type BAL was shown to catalyze the oligomerization of formaldehyde into GA and DHA. However, catalytic efficiency for the FR $\left(k_{\text {cat }} / K_{\mathrm{M}}=50 \mathrm{mM}^{-1} . \mathrm{s}^{-1}\right)$ was 36000 times slower than for benzoin production. The active site was thus swimmingly engineered to accept formaldehyde as donor substrate instead of benzaldehyde with the introduction of seven mutations. Four mutations, A28I, A394G, G419N, and $\mathrm{A} 480 \mathrm{~W}$, were introduced with computational redesign of the active site. Figure 19 features the active site of the enzyme with the thiazo ring fragment (red circle) bonded to DHA intermediate (purple). The four mentioned mutations are indicated in blue. The A394G/A480W mutations were introduced to fill the gap in the active site to improve formaldehyde recognition. Reverting A28I and G419N induced about 2-fold and 4-fold decrease of FLS activity respectively. This suggests that new and productive interactions were created between the introduced isoleucine and asparagine and FR intermediate. ${ }^{104}$ One extra mutation, L90T, was identified thanks to a round of computationally assisted site-directed mutagenesis. Finally, error-prone PCR highlighted two surface mutations, W89R and R188H. Thereby, FLS displays a 94-fold increase of the catalytic efficiency for the FR $\left(k_{\text {cat }} / K_{\mathrm{M}}=4700 \mathrm{mM}^{-1} \cdot \mathrm{s}^{-1}\right)$ compared to the initial BAL. In addition, no activity for the benzoin reaction at concentrations up to $10 \mu \mathrm{M}$ of enzyme and $20 \mathrm{mM}$ of benzaldehyde was detected for FLS.

Glycolaldehyde synthase (GALS) was recently engineered to produce GA from formaldehyde in $90 \%$ yield at $67 \mathrm{mM}$ of formaldehyde. ${ }^{107}$ An important feature of this work is the use of 
formaldehyde as a key $\mathrm{C}_{1}$ synthon to produce Acetyl-CoA thanks to an enzyme cascade reaction. The discovery of GALS is reminiscent of that of FLS because it was selected among ThDP-dependent enzymes and further engineered through several rounds of mutagenesis. The seven mutations used for FLS were notably tested. However, the final product is not chiral and this work is not further described in the present review.

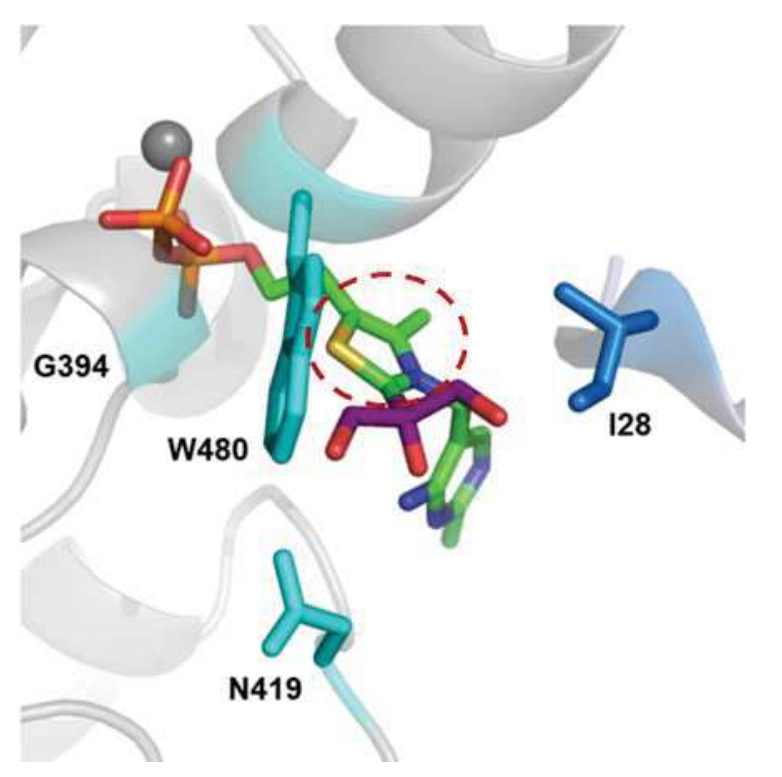

Figure 19. Model of FLS active site (PDB ID: 4QQ8) with the four computationally-designed mutations (blue) and the three-carbon intermediate (purple) linked to ThDP co-factor corresponding to intermediate iii) of Figure 18. ${ }^{103-104}$ The 3D structure of the intermediate was built and geometrically optimized by using Avogadro software, v1.1.1. The figure was then prepared using PyMol Molecular Graphics System, v0.99 (Schrödinger).

\subsection{Cascade FLS/FSA reaction: toward chiral higher monosaccharides}

The synthesized GA and DHA are not chiral molecules. In 2017, a cascade reaction used FLS and FSA to generate chiral carbohydrates. ${ }^{108}$ Surprisingly, FLS was active even in absence of the ThDP co-factor. L-erythrulose $\left(\mathrm{C}_{4}, \mathbf{4 0}\right)$ and L-sorbose $\left(\mathrm{C}_{6}, \mathbf{4 1}\right)$ were selectively obtained in $66 \%$ and $43 \%$ isolated yield, respectively (Figure 20). Compound 40 is obtained from the FLS-

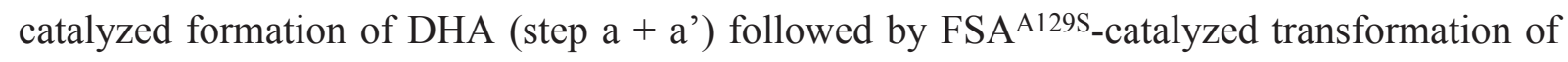
DHA with formaldehyde (step b). Compound $\mathbf{4 1}$ is obtained from the FLS-catalyzed formation of GA (step a), followed by FSA-catalyzed transformation of GA with formaldehyde into Lglyceraldehyde (step c). Further FSA ${ }^{\mathrm{A} 129 \mathrm{~S}}$-catalyzed transformation of L-glyceraldehyde with 
formaldehyde gave rise to $\mathbf{4 1}$ (step d). The latter strategy is an elegant example of symbiosis between FLS, FSA and the mono-mutant FSA ${ }^{\text {A129S }}{ }^{72}$ Wild-type FSA preferentially uses GA compared to DHA thus enabling step c to occur before its subsequent transformation into DHA in step a'. With favorable kinetics on DHA compared to GA (Table 1), the mono-mutant FSA $^{\mathrm{A} 129 \mathrm{~S}}$ is then added subsequently in a one pot-two step procedure.
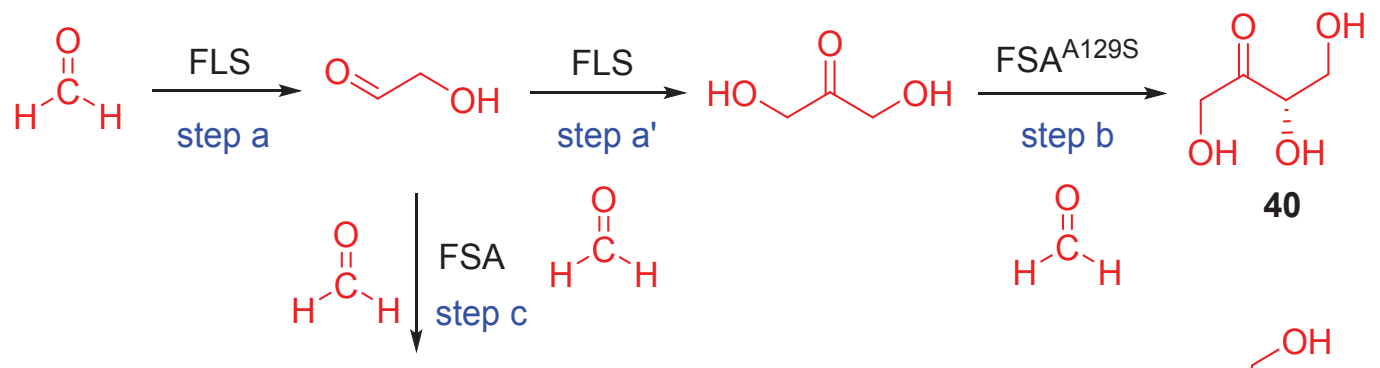

40

Figure 20. FLS/FSA cascade reaction: synthesis of compounds 40 and 41

\section{CONCLUSION}

In the context of the depletion of fossil resources, formaldehyde is an emerging $C_{1}$ source. ${ }^{17-23}$ Compared to the most studied $\mathrm{C}_{1}$ molecules $\left(\mathrm{CO}_{2}, \mathrm{CO}, \mathrm{HCOOH}\right.$, and $\left.\mathrm{CH}_{4}\right)$, formaldehyde is a particularly versatile and reactive substrate, making it a very difficult source to control but offering great promise for the synthesis of value-added chiral products.

The formose reaction is a perfect summary of the duality encountered in formaldehyde use: this remarkable reaction enables to build carbohydrates from formaldehyde as the only substrate. From this achiral and symmetrical building block, the gain in complexity is impressive with the generation of a carbon chain and chiral centers. Although those features have attracted interest in the fields of synthetic as well as prebiotic chemistry, understanding and control of this reaction remains largely unsolved challenges. ${ }^{109}$

Biocatalyzed transformations are powerful answers to these specific issues, because enzymes afford high selectivity, stereospecificity and stereochemical complementarity. ${ }^{9,36}$ The examples described in this publication show that aldol and umpolung reactions leads to complex valueadded products with perfect stereocontrol and without the need for protective groups. Aldolase catalysis has witnessed a large development from the first discoveries to the most recent 
examples. FSA and its mutants have notably enabled an increasing tolerance toward the use of formaldehyde as an acceptor. The engineered FLS is another noticeable breakthrough achieving the difficult task of controlling formaldehyde oligomerization. Aldol and umpolung are combined in the last result described in the present paper: an impressive gain in complexity is indeed reached with a FSA/FLS cascade catalyzing the transformation of the simple and achiral formaldehyde substrate into a perfectly stereocontrolled $\mathrm{C}_{4}$ and $\mathrm{C}_{6}$ carbohydrates.

These results are of high interest since the resultant $\beta$ - and $\gamma$-hydroxycarbonyl compounds (in particular carbohydrates) are biologically-relevant and thus of interest to the pharmaceutical industry. ${ }^{110-112}$

Finally, the present publication highlights the importance of i) enzyme discovery, ii) mechanism understanding and iii) enzyme engineering. The combination of these three approaches is instrumental in providing highly stereospecific biocatalysts dedicated to synthetic chemistry. Although the scope of product is still relatively narrow, this perspective shows that newer developments are expected to exploit the full potential of formaldehyde as a reactive $C_{1}$ source for the generation of high value-added chemicals. 


\section{References}

1. Reuss, G.; Disteldorf, W.; Gamer, A. O.; Hilt, A., Formaldehyde in Ullmann's Encyclopedia of Industrial Chemistry, Wiley, Weinheim. 2003.

2. Salthammer, T.; Mentese, S.; Marutzky, R. Formaldehyde in the Indoor Environment. Chem. Rev. 2010, $110,2536-2572$.

3. Salthammer, T. Formaldehyde in the Ambient Atmosphere: From an Indoor Pollutant to an Outdoor Pollutant? Angew. Chem. Int. Ed. 2013, 52, 3320-3327.

4. Meninno, S.; Lattanzi, A. Asymmetric Aldol Reaction with Formaldehyde: A Challenging Process. Chem. Rec. 2016, 16, 2016-2030.

5. Zafar, I.; Senad, N. The Formose Reaction: A Tool to Produce Synthetic Carbohydrates within a Regenerative Life Support System. Curr. Org. Chem. 2012, 16, 769-788.

6. Delidovich, I. V.; Simonov, A. N.; Taran, O. P.; Parmon, V. N. Catalytic Formation of Monosaccharides: From the Formose Reaction towards Selective Synthesis. ChemSusChem 2014, 7, 1833-1846.

7. Hönig, M.; Sondermann, P.; Turner, N. J.; Carreira, E. M. Enantioselective Chemo- and Biocatalysis: Partners in Retrosynthesis. Angew. Chem. Int. Ed. 2017, 56, 8942-8973.

8. Clapés, P.; Garrabou, X. Current Trends in Asymmetric Synthesis with Aldolases. Adv. Synth. Catal. 2011, $353,2263-2283$.

9. Clapés, P.; Fessner, W.-D.; Sprenger, G. A.; Samland, A. K. Recent Progress in Stereoselective Synthesis with Aldolases. Curr. Opin. Chem. Biol. 2010, 14, 154-167.

10. Busto, E. Recent Developments in the Preparation of Carbohydrate Derivatives from Achiral Building Blocks by using Aldolases. ChemCatChem 2016, 8, 2589-2598.

11. Yurimoto, H.; Kato, N.; Sakai, Y. Assimilation, Dissimilation, and Detoxification of Formaldehyde, a Central Metabolic Intermediate of Methylotrophic Metabolism. Chem. Rec. 2005, 5, 367-375.

12. Vorholt, J. A. Cofactor-Dependent Pathways of Formaldehyde Oxidation in Methylotrophic Bacteria. Arch. Microbiol. 2002, 178, 239-249.

13. Chistoserdova, L.; Gomelsky, L.; Vorholt, J. A.; Gomelsky, M.; Tsygankov, Y. D.; Lidstrom, M. E. Analysis of two Formaldehyde Oxidation Pathways in Methylobacillus flagellatus KT, a Ribulose Monophosphate Cycle Methylotroph. Microbiology 2000, 146, 233-238.

14. Cui, W.-G.; Zhang, G.-Y.; Hu, T.-L.; Bu, X.-H. Metal-Organic Framework-based Heterogeneous Catalysts for the Conversion of $\mathrm{C}_{1}$ Chemistry: $\mathrm{CO}, \mathrm{CO}_{2}$ and $\mathrm{CH}_{4}$. Coord. Chem. Rev. 2019, 387, 79-120.

15. Mesters, C. A Selection of Recent Advances in $\mathrm{C}_{1}$ Chemistry. Annu. Rev. Chem. Biomol. Eng. 2016, 7, 223-238.

16. Fierro, J. L. G. Catalysis in $\mathrm{C}_{1}$ Chemistry: Future and prospect. Catal. Lett. 1993, 22, 67-91.

17. Zhang, J.; Xing, C.; Tiwari, B.; Chi, Y. R. Catalytic Activation of Carbohydrates as Formaldehyde Equivalents for Stetter Reaction with Enones. J. Am. Chem. Soc. 2013, 135, 8113-8116.

18. He, H.; Edlich-Muth, C.; Lindner, S. N.; Bar-Even, A. Ribulose Monophosphate Shunt Provides Nearly All Biomass and Energy Required for Growth of E. coli. ACS Synth. Biol. 2018, 7, 1601-1611.

19. Deng, J.; Pan, T.; Xu, Q.; Chen, M.-Y.; Zhang, Y.; Guo, Q.-X.; Fu, Y. Linked Strategy for the Production of Fuels via Formose Reaction. Sci. Rep. 2013, 3, 1244-1244.

20. Jin, G.; Werncke, C. G.; Escudié, Y.; Sabo-Etienne, S.; Bontemps, S. Iron-Catalyzed Reduction of $\mathrm{CO}_{2}$ into Methylene: Formation of C-N, C-O, and C-C Bonds. J. Am. Chem. Soc. 2015, 137, 9563-9566.

21. Bontemps, S.; Vendier, L.; Sabo-Etienne, S. Ruthenium-Catalyzed Reduction of Carbon Dioxide to Formaldehyde. J. Am. Chem. Soc. 2014, 136, 4419-4425.

22. Heim, L. E.; Konnerth, H.; Prechtl, M. H. G. Future Perspectives for Formaldehyde: Pathways for Reductive Synthesis and Energy Storage. Green Chem. 2017, 19, 2347-2355.

23. Bontemps, S. Boron-Mediated Activation of Carbon Dioxide. Coord. Chem. Rev. 2016, 308, 117-130.

24. Feldman, M. Y., Reactions of Nucleic Acids and NucleoDroteins with Formaldehyde. Translated by A. L. Pumpiansky, Moscow. In Prog. Nucleic Acid Res. Mol. Biol., Davidson, J. N.; Cohn, W. E., Eds. Academic Press: 1973; Vol. 13, pp 1-49.

25. Hansen, B. A.; Lane, R. S.; Dekker, E. E. Formaldehyde Binding by 2-Keto-4-hydroxyglutarate Aldolase: Formation and Characterization of an Inactive Aldolase-Fromaldehyde-Cyanide Adduct. J. Biol. Chem. 1974, 249, 4891-4896.

26. Powers, S. G.; Snell, E. E. Ketopantoate hydroxymethyltransferase. II. Physical, Catalytic, and Regulatory Properties. J. Biol. Chem. 1976, 251, 3786-3793.

27. Bystrykh, L. V.; Sokolov, A. P.; Trotsenko, Y. A. Purification and Properties of Dihydroxyacetone Synthase from the Methylotrophic yeast Candida boidinii. FEBS Lett. 1981, 132, 324-328.

28. Paszkowski, A. Some Properties of Serine: Glyoxylate Aminotransferase from Rye Seedlings (Secale cereale L.). Acta Biochim. Pol. 1991, 38, 437-48. 
29. Chueskul, S.; Chulavatnatol, M. Properties of $\alpha$-Hydroxynitrile Lyase from the Petiole of Cassava (Manihot esculenta Crantz). Arch. Biochem. Biophys. 1996, 334, 401-405.

30. Fraenkel-Conrat, H.; Cooper, M.; Olcott, H. S. The Reaction of Formaldehyde with Proteins. J. Am. Chem. Soc. 1945, 67, 950-954.

31. Fraenkel-Conrat, H.; Brandon, B. A.; Olcott, H. S. The Reaction of Formaldehyde with Proteins: IV. Participation of Indole Groups. Gramicidin. J. Biol. Chem. 1947, 168, 99-118.

32. Fraenkel-Conrat, H.; Olcott, H. S. Reaction of Formaldehyde with Proteins: VI. Cross-Linking of Amino Groups with Phenol, Imidazole, or Indole Groups. J. Biol. Chem. 1948, 174, 827-843.

33. Fraenkel-Conrat, H.; Olcott, H. S. The Reaction of Formaldehyde with Proteins. V. Cross-linking between Amino and Primary Amide or Guanidyl Groups. J. Am. Chem. Soc. 1948, 70, 2673-2684.

34. Fraenkel-Conrat, H.; Mecham, D. K. The Reaction of Formaldehyde with Proteins: VII. Demonstration of Intermolecular Cross-Linking by Means of Osmotic Pressure Measurements. J. Biol. Chem. 1949, 177, 477-486. 35. Fessner, W. D.; Schneider, A.; Held, H.; Sinerius, G.; Walter, C.; Hixon, M.; Schloss, J. V. The Mechanism of Class II, Metal-Dependent Aldolases. Angew. Chem. Int. Ed. 1996, 35, 2219-2221.

36. Brovetto, M.; Gamenara, D.; Saenz Méndez, P.; Seoane, G. A. C-C Bond-Forming Lyases in Organic Synthesis. Chem. Rev. 2011, 111, 4346-4403.

37. Mlynarski, J.; Gut, B. Organocatalytic Synthesis of Carbohydrates. Chem. Soc. Rev. 2012, 41, 587-596.

38. Tittmann, K. Sweet siblings with different faces: The mechanisms of FBP and F6P Aldolase, Transaldolase, Transketolase and Phosphoketolase Revisited in Light of Recent Structural Data. Bioorg. Chem. 2014, 57, 263280.

39. Lehwess-Litzmann, A.; Neumann, P.; Parthier, C.; Lüdtke, S.; Golbik, R.; Ficner, R.; Tittmann, K. Twisted Schiff Base Intermediates and Substrate Locale Revise Transaldolase Mechanism. Nat. Chem. Biol. 2011, 7, 678684.

40. Renwick, S. B.; Snell, K.; Baumann, U. The Crystal Structure of Human Cytosolic Serine Hydroxymethyltransferase: A Target for Cancer Chemotherapy. Structure 1998, 6, 1105-1116.

41. Jagath, J. R.; Sharma, B.; Rao, N. A.; Savithri, H. S. The Role of His-134, -147, and -150 Residues in Subunit Assembly, Cofactor Binding, and Catalysis of Sheep Liver Cytosolic Serine Hydroxymethyltransferase. J. Biol. Chem. 1997, 272, 24355-24362.

42. Hift, H.; Mahler, H. R. The Enzymatic Condensation of Pyruvate and Formaldehyde. J. Biol. Chem. 1952, 198, 901-914.

43. Rea, D.; Hovington, R.; Rakus, J. F.; Gerlt, J. A.; Fülöp, V.; Bugg, T. D. H.; Roper, D. I. Crystal Structure and Functional Assignment of YfaU, a Metal Ion Dependent Class II Aldolase from Escherichia coli K12. Biochemistry 2008, 47, 9955-9965.

44. Griffiths, J. S.; Cheriyan, M.; Corbell, J. B.; Pocivavsek, L.; Fierke, C. A.; Toone, E. J. A Bacterial Selection for the Directed Evolution of Pyruvate Aldolases. Bioorg. Med. Chem. 2004, 12, 4067-4074.

45. Hernandez, K.; Bujons, J.; Joglar, J.; Charnock, S. J.; Domínguez de María, P.; Fessner, W. D.; Clapés, P. Combining Aldolases and Transaminases for the Synthesis of 2-Amino-4-hydroxybutanoic Acid. ACS Catal. 2017, 7, 1707-1711.

46. Beisswenger, R.; Kula, M. Catalytic Properties and Substrate Specificity of 3-Hexulose Phosphate Synthase from Methylomonas M15. Appl. Microbiol. Biotechnol. 1991, 34, 604-607.

47. Beisswenger, R.; Snatzke, G.; Thiem, J.; Kula, M. R. Enzyme-Catalyzed Aldol Reactions with 3-Hexulose Phosphate Synthase. Tetrahedron Lett. 1991, 32, 3159-3162.

48. Alexander, F. W.; Sandmeier, E.; Mehta, P. K.; Christen, P. Evolutionary Relationships among Pyridoxal-5'-Phosphate-Dependent Enzymes. Eur. J. Biochem. 1994, 219, 953-960.

49. Nozaki, H.; Kuroda, S.; Watanabe, K.; Yokozeki, K. Screening of Microorganisms Producing $\alpha-$ Methylserine Hydroxymethyltransferase, Purification of the Enzyme, Gene Cloning, and Application to the Enzymatic Synthesis of $\alpha$-Methyl-L-Serine. J. Mol. Catal. B: Enzym. 2009, 56, 221-226.

50. Nozaki, H.; Kuroda, S.; Watanabe, K.; Yokozeki, K. Gene Cloning of $\alpha$-Methylserine Aldolase from Variovorax paradoxus and Purification and Characterization of the Recombinant Enzyme. Biosci. Biotechnol. Biochem. 2008, 72, 2580-2588.

51. Nozaki, H.; Kuroda, S.; Watanabe, K.; Yokozeki, K. Purification and Gene Cloning of $\alpha$-Methylserine Aldolase from Ralstonia sp. Strain AJ110405 and Application of the Enzyme in the Synthesis of $\alpha$-Methyl-LSerine. Appl. Environ. Microbiol. 2008, 74, 7596-7599.

52. Nozaki, H.; Kuroda, S.; Watanabe, K.; Yokozeki, K. Gene Cloning, Purification, and Characterization of $\alpha$-Methylserine Aldolase from Bosea sp. AJ110407 and its Applicability for the Enzymatic Synthesis of $\alpha$-MethylL-Serine and $\alpha$-Ethyl-L-serine. J. Mol. Catal. B: Enzym. 2009, 59, 237-242.

53. Barbas, C. F.; Wang, Y. F.; Wong, C. H. Deoxyribose-5-Phosphate Aldolase as a Synthetic Catalyst. J. Am. Chem. Soc. 1990, 112, 2013-2014. 
54. Bednarski, M. D.; Simon, E. S.; Bischofberger, N.; Fessner, W. D.; Kim, M. J.; Lees, W.; Saito, T.; Waldmann, H.; Whitesides, G. M. Rabbit Muscle Aldolase as a Catalyst in Organic Synthesis. J. Am. Chem. Soc. 1989, 111, 627-635.

55. St-Jean, M.; Sygusch, J. Stereospecific Proton Transfer by a Mobile Catalyst in Mammalian Fructose-1,6bisphosphate Aldolase. J. Biol. Chem. 2007, 282, 31028-31037.

56. Brockamp, H. P.; Kula, M. R. Staphylococcus carnosus Aldolase as Catalyst for Enzymatic Aldol Reactions. Tetrahedron Lett. 1990, 31, 7123-7126.

57. Brockamp, H. P.; Kula, M. R. Purification and Characterization of a Class I Fructose 1,6-Bisphosphate Aldolase from Staphylococcus carnosus. Appl. Microbiol. Biotechnol. 1990, 34, 287-91.

58. Schoevaart, R.; van Rantwijk, F.; Sheldon, R. A. Class I Fructose-1,6-bisphosphate Aldolases as Catalysts for Asymmetric Aldol Reactions. Tetrahedron: Asymmetry 1999, 10, 705-711.

59. Schoevaart, R.; Van Rantwijk, F.; Sheldon, R. A. Facile Enzymatic Aldol Reactions with Dihydroxyacetone in the Presence of Arsenate. J. Org. Chem. 2001, 66, 4559-4562.

60. Yang, J.; Li, J.; Men, Y.; Zhu, Y.; Zhang, Y.; Sun, Y.; Ma, Y. Biosynthesis of L-Sorbose and L-Psicose Based on C-C Bond Formation Catalyzed by Aldolases in an Engineered Corynebacterium glutamicum Strain. Appl. Environ. Microbiol. 2015, 81, 4284-4294.

61. Fessner, W.-D.; Sinerius, G.; Schneider, A.; Dreyer, M.; Schulz, G. E.; Badia, J.; Aguilar, J. Diastereoselective Enzymatic Aldol Additions: L-Rhamnulose and L-Fuculose 1-Phosphate Aldolases from E. coli. Angew. Chem. Int. Ed. 1991, 30, 555-558.

62. Sugiyama, M.; Hong, Z.; Whalen, L. J.; Greenberg, W. A.; Wong, C. H. Borate as a Phosphate Ester Mimic in Aldolase-Catalyzed Reactions: Practical Synthesis of L-Fructose and L-Iminocyclitols. Adv. Synth. Catal. 2006, 348, 2555-2559.

63. Garrabou, X.; Joglar, J.; Parella, T.; Crehuet, R.; Bujons, J.; Clapés, P. Redesign of the Phosphate Binding Site of L-Rhamnulose-1-phosphate Aldolase towards a Dihydroxyacetone Dependent Aldolase. Adv. Synth. Catal. 2011, 353, 89-99.

64. Schürmann, M.; Sprenger, G. A. Fructose-6-phosphate Aldolase Is a Novel Class I Aldolase from Escherichia coli and Is Related to a Novel Group of Bacterial Transaldolases. J. Biol. Chem. 2001, 276, $11055-$ 11061.

65. Thorell, S.; Schürmann, M.; Sprenger, G. A.; Schneider, G. Crystal Structure of Decameric Fructose-6Phosphate Aldolase from Escherichia Coli Reveals Inter-subunit Helix Swapping as a Structural Basis for Assembly Differences in the Transaldolase Family. J. Mol. Biol. 2002, 319, 161-171.

66. Schürmann, M.; Schürmann, M.; Sprenger, G. A. Fructose 6-Phosphate Aldolase and 1-Deoxy-D-xylulose 5-Phosphate Synthase from Escherichia Coli as Tools in Enzymatic Synthesis of 1-Deoxysugars. J. Mol. Catal. B: Enzym. 2002, 19-20, 247-252.

67. Sugiyama, M.; Hong, Z.; Liang, P.-H.; Dean, S. M.; Whalen, L. J.; Greenberg, W. A.; Wong, C.-H. DFructose-6-phosphate Aldolase-catalyzed One-Pot Synthesis of Iminocyclitols. J. Am. Chem. Soc. 2007, 129, 14811-14817.

68. Güclü, D.; Szekrenyi, A.; Garrabou, X.; Kickstein, M.; Junker, S.; Clapés, P.; Fessner, W.-D. Minimalist Protein Engineering of an Aldolase Provokes Unprecedented Substrate Promiscuity. ACS Catal. 2016, 6, 18481852.

69. Garrabou, X.; Castillo, J. A.; Guérard-Hélaine, C.; Parella, T.; Joglar, J.; Lemaire, M.; Clapés, P. Asymmetric Self- and Cross-aldol Reactions of Glycolaldehyde Catalyzed by D-Fructose-6-phosphate Aldolase. Angew. Chem. Int. Ed. 2009, 121, 5629-5633.

70. Concia, A. L.; Lozano, C.; Castillo, J. A.; Parella, T.; Joglar, J.; Clapés, P. D-Fructose-6-phosphate Aldolase in Organic Synthesis: Cascade Chemical-Enzymatic Preparation of Sugar-Related Polyhydroxylated Compounds. Chem. Eur. J. 2009, 15, 3808-3816.

71. Guérard-Hélaine, C.; Légeret, B.; Fernandes, C.; Prévot, V.; Forano, C.; Lemaire, M. Efficient Immobilization of Fructose-6-phosphate Aldolase in Layered Double Hydroxide: Improved Stereoselective Synthesis of Sugar Analogues. New J. Chem. 2011, 35, 776-779.

72. Castillo, J. A.; Guérard-Hélaine, C.; Gutiérrez, M.; Garrabou, X.; Sancelme, M.; Schürmann, M.; Inoue, T.; Hélaine, V.; Charmantray, F.; Gefflaut, T.; Hecquet, L.; Joglar, J.; Clapés, P.; Sprenger, G. A.; Lemaire, M. A Mutant D-Fructose-6-phosphate Aldolase (Ala129Ser) with Improved Affinity towards Dihydroxyacetone for the Synthesis of Polyhydroxylated Compounds. Adv. Synth. Catal. 2010, 352, 1039-1046.

73. Hélaine, V.; Mahdi, R.; Sudhir Babu, G. V.; de Berardinis, V.; Wohlgemuth, R.; Lemaire, M.; GuérardHélaine, C. Straightforward Synthesis of Terminally Phosphorylated L-Sugars via Multienzymatic Cascade Reactions. Adv. Synth. Catal. 2015, 357, 1703-1708.

74. Szekrenyi, A.; Garrabou, X.; Parella, T.; Joglar, J.; Bujons, J.; Clapés, P. Asymmetric Assembly of Aldose Carbohydrates from Formaldehyde and Glycolaldehyde by Tandem Biocatalytic Aldol Reactions. Nat. Chem. 2015, 7, 724-729. 
75. Gutierrez, M.; Parella, T.; Joglar, J.; Bujons, J.; Clapés, P. Structure-guided Redesign of D-Fructose-6phosphate Aldolase from E. coli: Remarkable Activity and Selectivity Towards Acceptor Substrates by Two-point Mutation. Chem. Comm. 2011, 47, 5762-5764.

76. Zhou, T.; Vallooran, J. J.; Assenza, S.; Szekrenyi, A.; Clapés, P.; Mezzenga, R. Efficient Asymmetric Synthesis of Carbohydrates by Aldolase Nano-confined in Lipidic Cubic Mesophases. ACS Catal. 2018, 8, 58105815 .

77. Nozaki, H.; Kuroda, S.; Watanabe, K.; Yokozeki, K. Cloning of the Gene Encoding $\alpha$-Methylserine Hydroxymethyltransferase from Aminobacter sp. AJ110403 and Ensifer sp. AJ110404 and Characterization of the Recombinant Enzyme. Biosci. Biotechnol. Biochem. 2008, 72, 3002-3005.

78. Bugaut, X.; Glorius, F. Organocatalytic Umpolung: N-Heterocyclic Carbenes and Beyond. Chem. Soc. Rev. 2012, 41, 3511-3522.

79. Kluger, R.; Tittmann, K. Thiamin Diphosphate Catalysis: Enzymic and Nonenzymic Covalent Intermediates. Chem. Rev. 2008, 108, 1797-1833.

80. Jordan, F. Current Mechanistic Understanding of Thiamin Diphosphate-Dependent Enzymatic Reactions. Nat. Prod. Rep. 2003, 20, 184-201.

81. Schörken, U.; Sprenger, G. A. Thiamin-dependent Enzymes as Catalysts in Chemoenzymatic Syntheses. Biochim. Biophys. Acta, Protein Struct. Mol. Enzymol. 1998, 1385, 229-243.

82. Breslow, R.; McNelis, E. On the Mechanism of Thiamine Action. VI.1 2-Acetylthiazolium Salts as "Active Acetate". J. Am. Chem. Soc. 1960, 82, 2394-2395.

83. Kern, D.; Kern, G.; Neef, H.; Tittmann, K.; Killenberg-Jabs, M.; Wikner, C.; Schneider, G.; Hübner, G. How Thiamine Diphosphate is Activated in Enzymes. Science 1997, 275, 67-70.

84. Breslow, R. Rapid Deuterium Exchange in Thiazolium Salts. J. Am. Chem. Soc. 1957, 79, 1762-1763.

85. Meyer, D.; Neumann, P.; Ficner, R.; Tittmann, K. Observation of a Stable Carbene at the Active Site of a Thiamin Enzyme. Nat. Chem. Biol. 2013, 9, 488.

86. Lee, J. K.; Houk, K. N. A Proficient Enzyme Revisited: The Predicted Mechanism for Orotidine Monophosphate Decarboxylase. Science 1997, 276, 942-945.

87. Grossmann, A.; Enders, D. N-Heterocyclic Carbene Catalyzed Domino Reactions. Angew. Chem. Int. Ed. 2012, 51, 314-325.

88. Douglas, J.; Churchill, G.; Smith, A. D. NHCs in Asymmetric Organocatalysis: Recent Advances in Azolium Enolate Generation and Reactivity. Synthesis 2012, 44, 2295-2309.

89. Dröge, T.; Glorius, F. The Measure of All Rings-N-Heterocyclic Carbenes. Angew. Chem. Int. Ed. 2010, 49, 6940-6952.

90. Holland, M. C.; Gilmour, R. Deconstructing Covalent Organocatalysis. Angew. Chem. Int. Ed. 2015, 54, 3862-3871.

91. Guo, Z.; Goswami, A.; Nanduri, V. B.; Patel, R. N. Asymmetric Acyloin Condensation Catalysed by Phenylpyruvate Decarboxylase. Part 2: Substrate Specificity and Purification of the Enzyme. Tetrahedron: Asymmetry 2001, 12, 571-577.

92. Demir, A. S.; Ayhan, P.; Igdir, A. C.; Duygu, A. N. Enzyme Catalyzed Hydroxymethylation of Aromatic Aldehydes with Formaldehyde. Synthesis of Hydroxyacetophenones and (S)-Benzoins. Tetrahedron 2004, 60, 6509-6512.

93. Waites, M. J.; Quayle, J. R. The Interrelation between Transketolase and Dihydroxyacetone Synthase Activities in the Methylotrophic Yeast Candida boidinii. Microbiology 1981, 124, 309-316.

94. Nobuo, K.; Toshio, H.; Chikahiro, S.; Tsutomu, N.; Yoshiki, T.; Hideaki, Y. Purification and Properties of a Transketolase Responsible for Formaldehyde Fixation in a Methanol-utilizing Yeast, Candida boidinii (Kloeckera sp.) No. 2201. Biochim. Biophys. Acta, Gen. Subjects 1982, 715, 143-150.

95. Guérard-Hélaine, C.; Moreira, M. D. S. L.; Touisni, N.; Hecquet, L.; Lemaire, M.; Hélaine, V. Transketolase-aldolase Symbiosis for the Stereoselective Preparation of Aldoses and Ketoses of Biological Interest. Adv. Synth. Catal. 2017, 359, 2061-2065.

96. Ruiz-Mirazo, K.; Briones, C.; de la Escosura, A. Prebiotic Systems Chemistry: New Perspectives for the Origins of Life. Chem. Rev. 2014, 114, 285-366.

97. Ricardo, A.; Carrigan, M. A.; Olcott, A. N.; Benner, S. A. Borate Minerals Stabilize Ribose. Science 2004, $303,196$.

98. Hein, J. E.; Blackmond, D. G. On the Origin of Single Chirality of Amino Acids and Sugars in Biogenesis. Acc. Chem. Res. 2012, 45, 2045-2054.

99. Matsumoto, T.; Yamamoto, H.; Inoue, S. Selective Formation of Triose from Formaldehyde Catalyzed by Thiazolium Salt. J. Am. Chem. Soc. 1984, 106, 4829-4832.

100. Shigemasa, Y.; Matsumoto, H.; Sasaki, Y.; Ueda, N.; Nakashima, R.; Harada, K.-I.; Takeda, N.; Suzuki, M. The Selective Formose Reaction in Dimethylformamide in the Presence of Vitamin B1. J. Carbohydr. Chem. 1983, 2, 343-348. 
101. Saimoto, H.; Kotani, K.; Shigemasa, Y.; Suzuki, M.; Harada, K.-i. Isolation of an Intermediate of Formose Reaction Catalyzed by Thiamin-HCl. Tetrahedron Lett. 1989, 30, 2553-2554.

102. Tajima, H.; Niitsu, T.; Inoue, H. Polymerization of Formaldehyde by an Immobilized Thiamine Catalyst on Cation-Exchange Resin. J. Chem. Eng. Jpn. 1999, 32, 776-782.

103. Siegel, J. B.; Smith, A. L.; Poust, S.; Wargacki, A. J.; Bar-Even, A.; Louw, C.; Shen, B. W.; Eiben, C. B.; Tran, H. M.; Noor, E.; Gallaher, J. L.; Bale, J.; Yoshikuni, Y.; Gelb, M. H.; Keasling, J. D.; Stoddard, B. L.; Lidstrom, M. E.; Baker, D. Computational Protein Design Enables a Novel one-Carbon Assimilation Pathway. Proc. Natl. Acad. Sci. 2015, 112, 3704-3709.

104. Poust, S.; Piety, J.; Bar-Even, A.; Louw, C.; Baker, D.; Keasling, J. D.; Siegel, J. B. Mechanistic Analysis of an Engineered Enzyme that Catalyzes the Formose Reaction. ChemBioChem 2015, 16, 1950-1954.

105. Enders, D.; Niemeier, O.; Henseler, A. Organocatalysis by N-Heterocyclic Carbenes. Chem. Rev. 2007, $107,5606-5655$.

106. Henrique Teles, J.; Melder, J.-P.; Ebel, K.; Schneider, R.; Gehrer, E.; Harder, W.; Brode, S.; Enders, D.; Breuer, K.; Raabe, G. The Chemistry of Stable Carbenes. Part 2. Benzoin-type Condensations of Formaldehyde Catalyzed by Stable Carbenes. Helv. Chim. Acta 1996, 79, 61-83.

107. Lu, X.; Liu, Y.; Yang, Y.; Wang, S.; Wang, Q.; Wang, X.; Yan, Z.; Cheng, J.; Liu, C.; Yang, X.; Luo, H.; Yang, S.; Gou, J.; Ye, L.; Lu, L.; Zhang, Z.; Guo, Y.; Nie, Y.; Lin, J.; Li, S.; Tian, C.; Cai, T.; Zhuo, B.; Ma, H.; Wang, W.; Ma, Y.; Liu, Y.; Li, Y.; Jiang, H. Constructing a Synthetic Pathway for Acetyl-coenzyme A from oneCarbon through Enzyme Design. Nat. Commun. 2019, 10, 1378.

108. Yang, J.; Sun, S.; Men, Y.; Zeng, Y.; Zhu, Y.; Sun, Y.; Ma, Y. Transformation of Formaldehyde into Functional Sugars via Multi-enzyme Stepwise Cascade Catalysis. Catal. Sci. Technol. 2017, 7, 3459-3463.

109. Béthegnies, A.; Escudié, Y.; Nuñez-Dallos, N.; Vendier, L.; Hurtado, J.; del Rosal, I.; Maron, L.; Bontemps, S. Reductive $\mathrm{CO}_{2}$ Homocoupling: Synthesis of a Borylated $\mathrm{C}_{3}$ Carbohydrate. ChemCatChem 2019, 11, $760-765$. 110. Adams, J. P.; Brown, M. J. B.; Diaz-Rodriguez, A.; Lloyd, R. C.; Roiban, G. D. Biocatalysis: A Pharma Perspective. Adv. Synth. Catal. 2019, 361, 2421-2432.

111. Ernst, B.; Magnani, J. L. From Carbohydrate Leads to Glycomimetic Drugs. Nat. Rev. Drug Discovery 2009, 8, 661 .

112. Fernández-Tejada, A.; Cañada, F. J.; Jiménez-Barbero, J. Recent Developments in Synthetic CarbohydrateBased Diagnostics, Vaccines, and Therapeutics. Chem. Eur. J. 2015, 21, 10616-10628. 